\title{
Early Treatments in Orthodontics
}

\author{
Ousehal Lahcen and Lazrak Laila \\ Department of Orthodontics, Faculty of Dentistry, Casablanca \\ Morocco
}

\section{Introduction}

It is said that Chinese physicians were paid only so long as their patients were in good health. Such an approach to healthcare lent physicians an incentive to develop preventive therapy to ensure their patients remained healthy.

Medicine in the 21st century strives to be preventive first and foremost, and so preventive and interceptive treatments hold once more an important place in the armamentarium of modern medicine. Dentistry and orthodontics are no exception to this rule.

Even so, current orthodontic practice still comprises two schools: some orthodontists favour early treatment before the permanent teeth have erupted, while others refuse this approach, to which they are radically opposed.

We consider that initiating early treatment is reasonable and eminently logical, because is allows partial or even total correction of an evolving orthodontic anomaly in a growing child. Such early therapy is often brief, uses simple means, elicits little cooperation from patients and their parents and prevents the anomaly from worsening. In defence of this approach GUGINO (1998) pointed out that the earlier the treatment was applied, the better the face adapted to it, whereas the longer it was deferred, the more it would have to adapt to the face.

Since then the orthodontic literature has abounded with reports on early orthodontic treatment: major orthodonticians who have advocated early orthodontic treatment include RICKETTS, GUGINO, MCNAMARA, DALE, FRANKEL, DELAIRE, GRABER, PHILLIPE, LANGLADE and BENCH.

However, we stress that early treatment is no simpler: on the contrary, it has to be based an overall analysis of the patient's condition, and so requires thorough knowledge of human growth, the physiology of the orofacial functions, the morphogenesis of the dental arches and child psychology. These basic considerations will help the practitioner choose the right therapy at the right time, thereby avoiding prolonged therapeutic efforts that are tiring for both children and their parents and discouraging for the practitioner.

Early treatments often fail to remedy anomalies entirely, but they greatly simplify subsequent orthodontic treatment. Children and their parents can thus expect a two-stage treatment.

The purpose of this chapter is to describe the early interceptive approach to different orthodontic anomalies. We will deal with the early treatment of dentomaxillary disharmonies, anterior open bites, Class II abnormalities and skeletal Class III abnormalities. We will illustrate our presentation with clinical examples. 


\section{Definitions and terminology}

McNamara defines early treatments in orthodontics as therapeutic procedures undertaken on deciduous or mixed dentition for the purpose of preventing, intercepting or correcting a specific orthodontic problem.

Some define early treatment in orthodontics as removable or fixed appliance intervention in the primary, early mixed (permanent first molars and incisors present), or midmixed(intertransitional period, before, before the emergence of first premolars and permanent mandibular canines).

Others define them as late-mixed dentition stage treatment (before the emergence of second premolars and permanent maxillary canines). (Ghafari and al 1998)

The American Association of Orthodontists' Council of Orthodontic Education defines interceptive orthodontics as "that phase of the science and art of orthodontics employed to recognize and eliminate potential irregularities and malpositions in the developing dentofacial complex." Orthodontics: Council on Orthodontic Education. St Louis;AAO:1971.

\section{Objectives of early orthodontic treatment}

Early orthodontic treatment aims to:

- Establish correct occlusion in both deciduous and permanent dentition (interceptive guidance of occlusion);

- Correct or reduce vertical or anteroposterior skeletal discrepancies ;

- Correct transverse asymmetry ;

- Favour the child's psychosocial integration;

- Forestall risk of tooth damage due to malocclusion (trauma, periodontal problems, etc.).

\section{Advantages and disadvantages of early treatment}

The workshop discussions on early orthodontic treatment, held by the american board of orthodontics in 1977, indicated that most participants considered early interventions as viable option in many malocclusions cases. Early treatment is suggested to bring about many benefits including better use of the patient growth potential, reduced need of extractions and orthognathic surgery, less risk for adverse iatrogenic effects, better patient compliance, and better and more stable results (KESKI-NISULA and al 2003)

The disadvantages of this approach are increased cost and duration of overall patient care, increased risk of caries and fatigue in both child and parents.

\section{Early interceptive therapy}

\subsection{Early treatment of dental crowding}

Crowding is often a sign of dentomaxillary disharmony (DMD).

This is defined as a misfit of the arch perimeter and the dental volume, which can be due to relative microdontia, with arch diastemas, or by relative macrodontia, causing arch crowding.

The early treatment of DMD due to relative macrodontia can be either preventive or interceptive. The preventive approach consists in ensuring that no arch space is lost. The deciduous dentition must thus be conserved, and if a milk tooth is lost, the space must be kept open by a fixed or removable device (Cases 1 and 2). If several deciduous teeth are lost, 


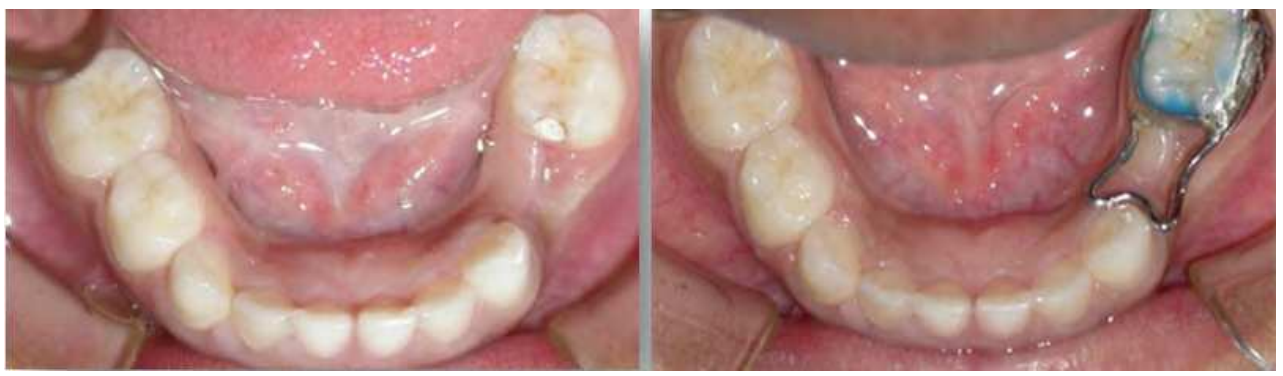

Case 1. Unilatéral space maintainer
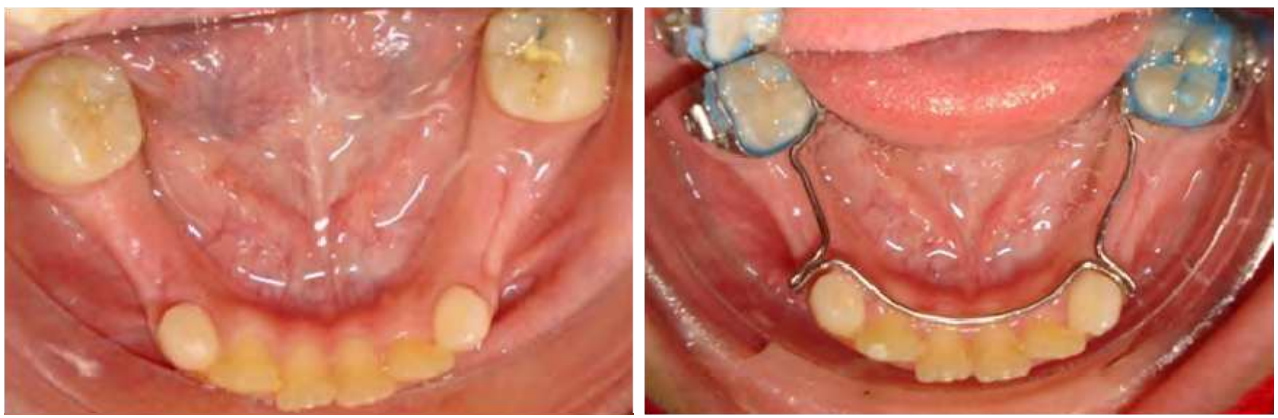

Case 2. Bilateral space maintainer
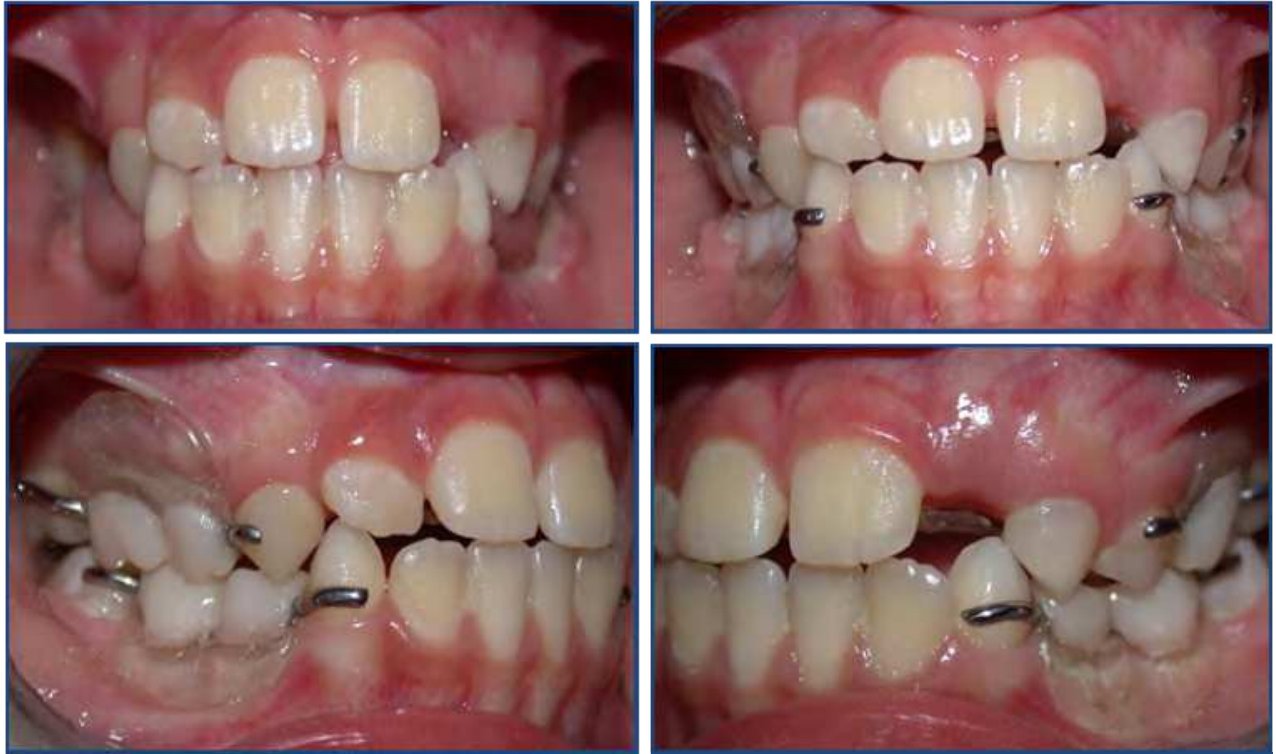

Case 3. Maintaining space by a removable paedodontic appliance 

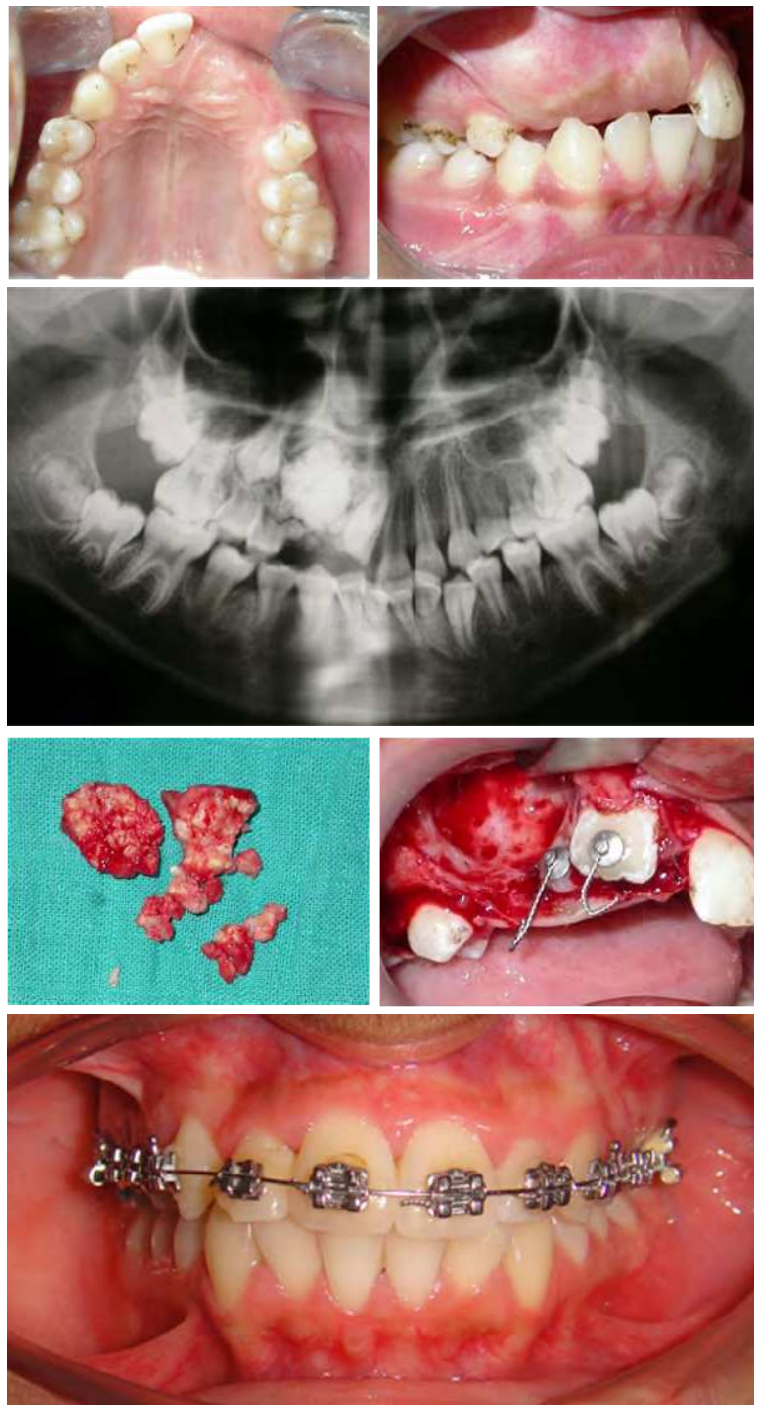

Case 4. Early treatment of the inclusion of teeth 11,12 and 13 due to dontoid formations

a paedodontic appliance will restore appearance and masticatory function, while retaining the space for the permanent teeth (Case 3)

If supernumerary teeth or odontoid formations are present, blocking the eruption of permanent teeth, they can be removed surgically as a preventive measure against crowding of permanent dentition (Case 4 and 5).

The interceptive approach will depend on the degree of crowding.

If the crowding is less than $6 \mathrm{~mm}$, a transverse or anterioposterior arch expansion is indicated, to increase the arch perimeter and so prepare enough space to accommodate the permanent teeth (Case 6). 

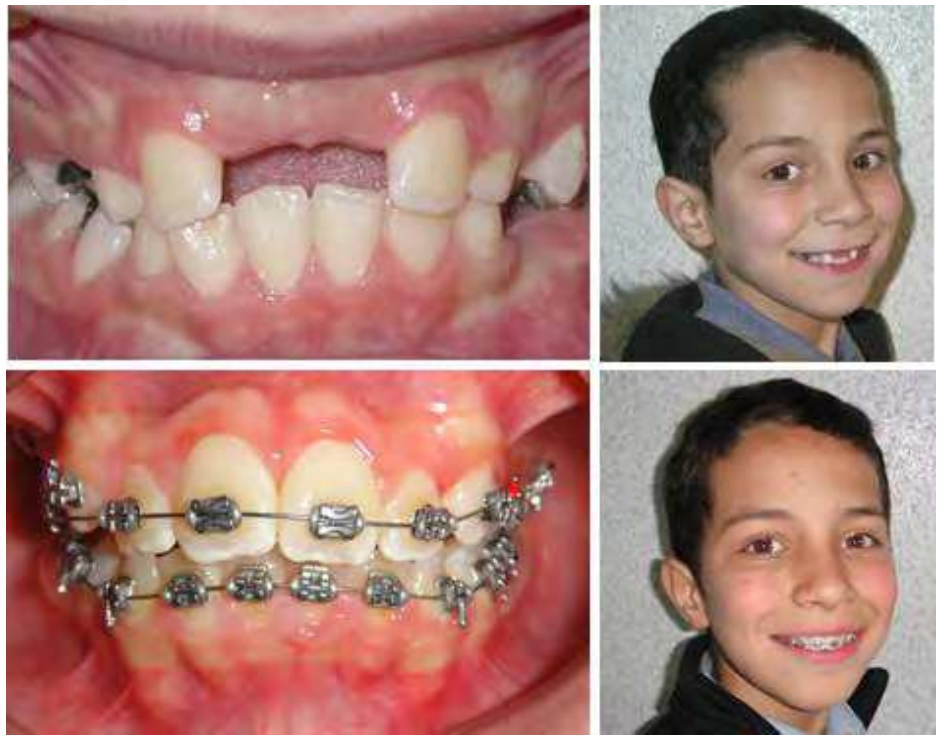

Case 5. Early treatment of the inclusion of 11 and 21
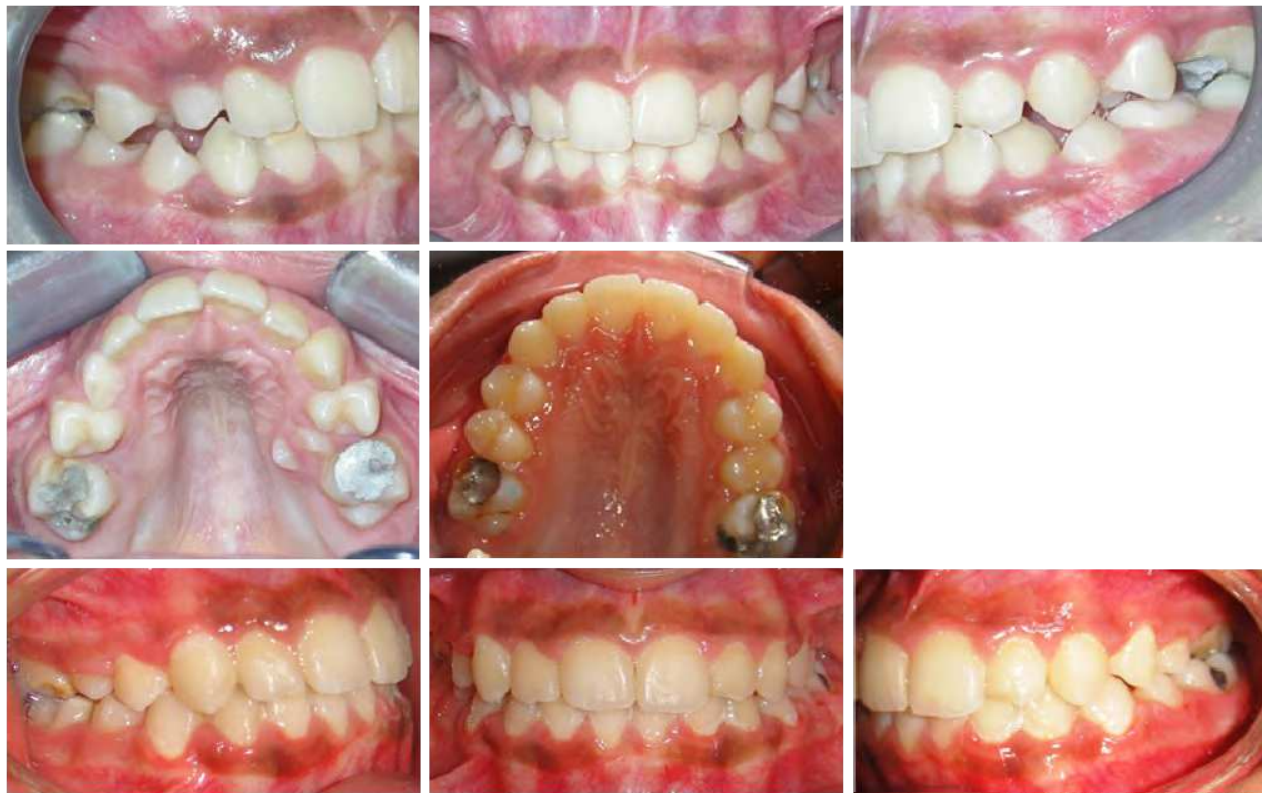

Case 6. Early treatment of lateral DMD bydistalization of maxillary molars

If the DMD exceeds $7 \mathrm{~mm}$, the interceptive approach of choice remains programmed extraction, also still called serial extractions or interceptive guidance of occlusion (J DALE) (Cases 7 and 8) 

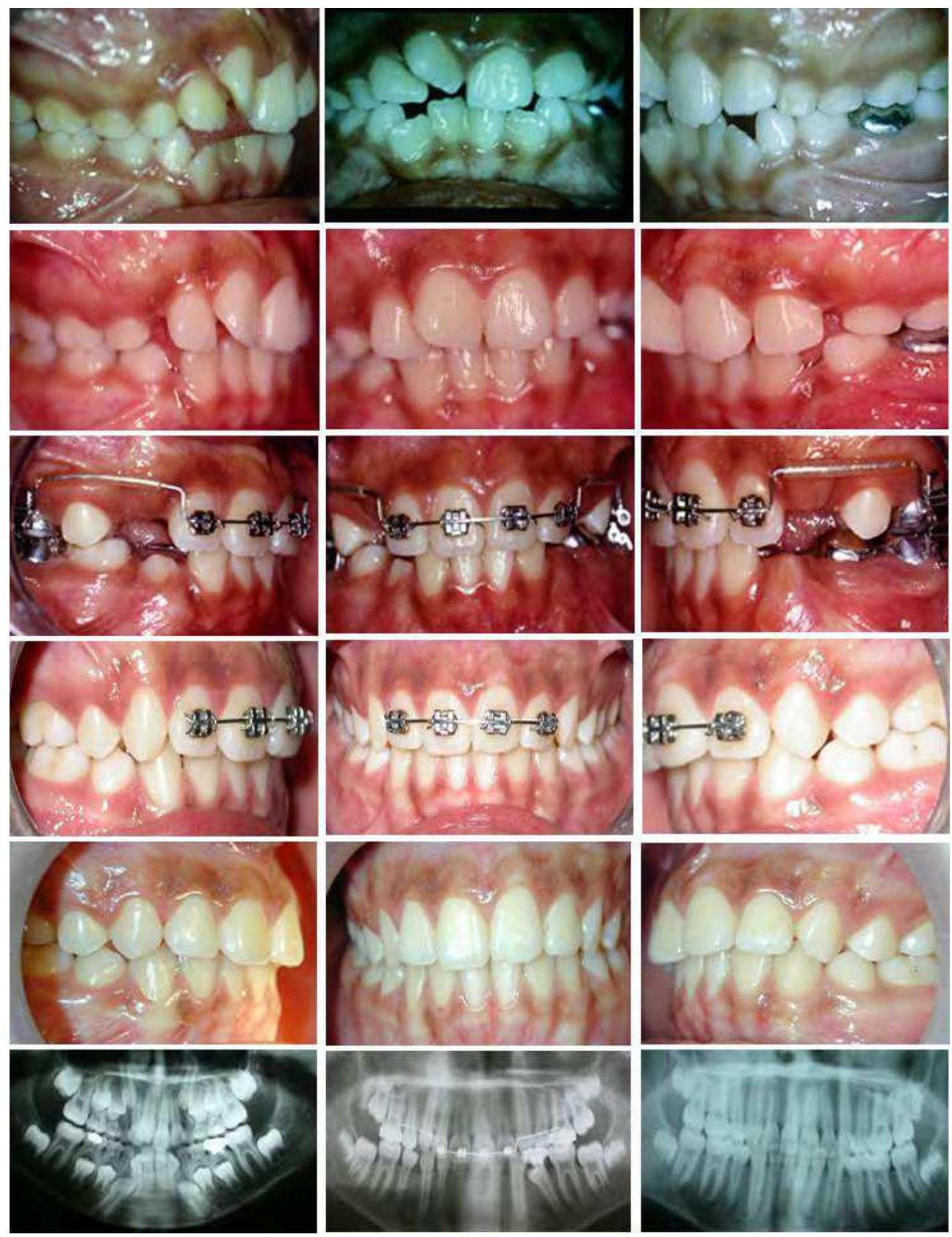

Case 7. Treatment of severe DMD in mixed dentition by serial extractions 

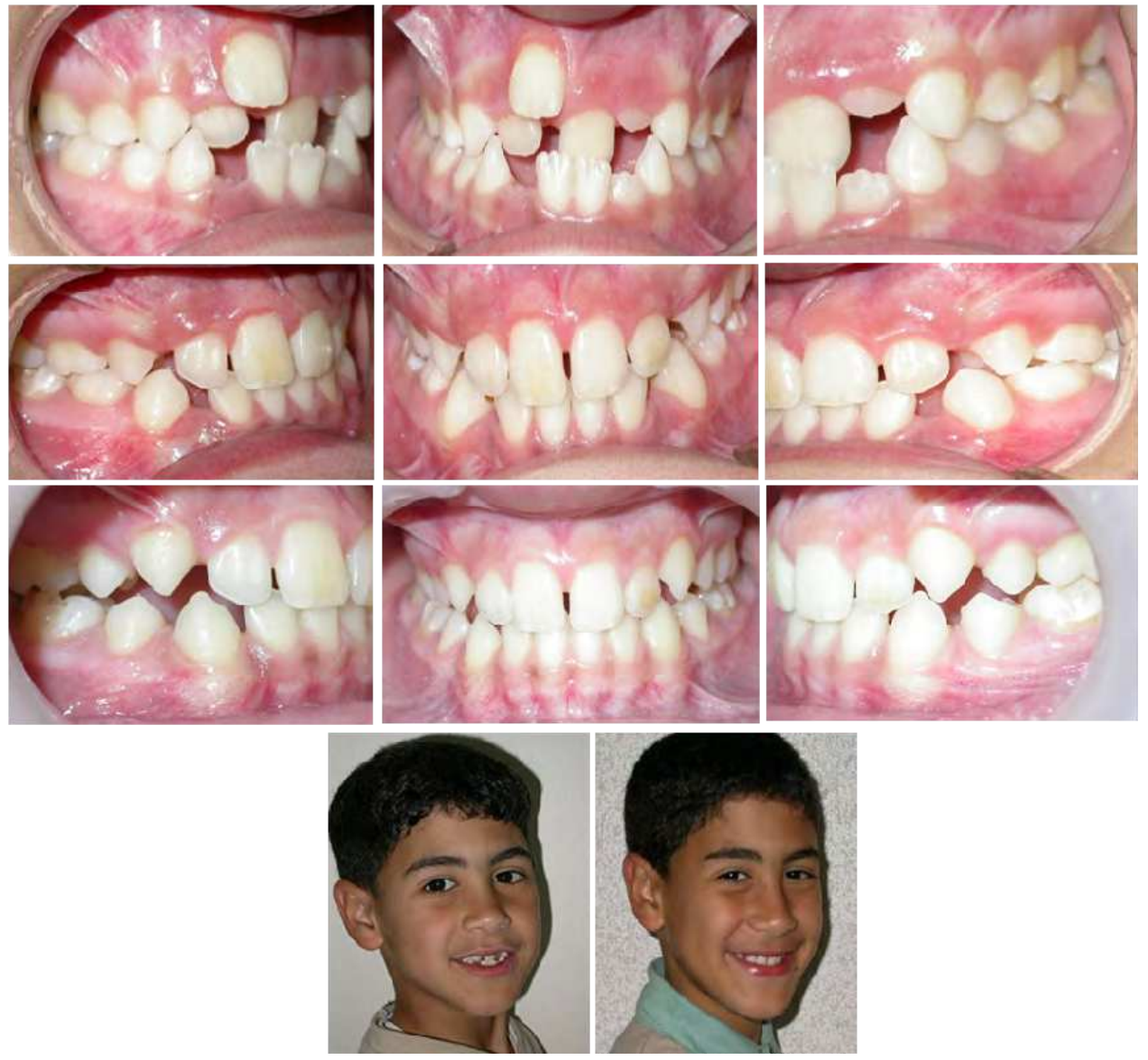

Case 8. Treatment of severe DMD in mixed dentition by serial extractions

ROBERT BUNON in "Essay on the Diseases of the Teeth," published as long ago as 1743 (1 in serial 13) was the first to describe these, but it was HOTZ (18 in serial 8) and KELLEGREEN (19 in serial 8) who first published the protocol, defined by DALE as interceptive guidance of occlusion.

Thus HOTZ, in a case of severe crowding in mixed dentition in a child with a favourable facial pattern, advocated extracting the deciduous canines at age 8 years, the first deciduous molars 6 months later, and then extracting the first premolars which have erupted. The aim is to make room for the permanent canines.

GRABER (1971) emphasised the fact that serial extractions are an orthodontic act and so must result from a precise diagnosis of the abnormality, which implies sound scientific knowledge and adequate clinical experience.

On programmed extractions, Dale (2000) wrote:

"Serial extraction ... nobody does that anymore! That was the comment that was made to me recently by an orthodontic educator. General practitioners are doing it, paediatric dentists are doing it, and if orthodontists are not doing it they are missing out, their patients are 
missing out, and ... so is orthodontics. Serial extraction is an excellent treatment procedure! It can reduce appliance treatment time, the cost of treatment, discomfort to patients, and time lost by both the patients and their parents. It is logical to intercept a malocclusion as early as possible, and to reduce, or in rare instances, to avoid multibanded, multibracket mechanotherapy at the sensitive teenage period".

The protocol often requires a multibracket treatment to complete it, but this is greatly simplified and of greatly shortened duration. This argues in favour of serial extractions, which thus reduce the overall cost of orthodontic treatment in children.

LITTLE et al. (1990) showed that cases treated by serial extraction were more stable in the long term as regards incisor alignment than cases treated later with extraction of four premolars and a conventional full brace treatment.

Similarly, PERSON et al. (1989) studied the stability of incisor alignment 30 years after treatment by comparing a sample of 42 cases treated by serial extraction and another sample of 29 untreated cases. He found no significant difference between the two groups.

\subsection{Early therapy for transverse abnormalities}

These abnormalities are the result of in sufficient or excessive transverse development of the basal bone or the alveolar arch. They can be maxillary or mandibular. Special attention must be paid to the mandibular lateral deviation caused by the maxillary transverse deficit (EGERMARK-ERIKSSON et al. 1990, KUROL \& BERGLUND 1992).

This functional lateral deviation will be responsible for craniomandibular disorders: electromyographic studies have shown that the activity of temporal and masseter muscles is disturbed in children with a posterior crossbite (TROESTRUP B \&MÖLLER 1970, INGERVALL \& THILANDER 1975).

Other studies have shown that adolescents and adults presenting a posterior crossbite are more likely to develop cranio-mandibulaire disorders. If untreated, this lateral deviation can evolve with growth into a true laterognathy. This orthodontic abnormality is difficult to treat, often requiring orthognathic surgery in adulthood (PROFFIT 2002, McNAMARA 2002), whence the utility of treating such abnormalites early on. We take the view that addressing these abnormalities is a true orthodontic emergency. Transverse abnormalities are most often secondary to some orofacial dysfunction, such as atypical swallowing, buccal resorption or thumbsucking (LARSSON 1968, LINDER-ARONSON 1970, BEHLFELT 1989). The first early act to be undertaken will be to re-educate these functions.

Maxillary expansion will thus be initiated as early as possible to re-centre the mandible and so rebalance facial growth (KUTIN \& HAWES 1969, PROFFIT 2000, CLIFFORD 1971). This expansion can be achieved using a median screw expander (Case 10) or fixed appliances, of which the quad helix is the device of choice (Case 11 and 12). This expander is used specifically for basal maxillary insufficiency (endognathy). The purpose of the device is to expand the median palatine suture. One type can be inserted into attachments bonded or welded to molar or premolar bands. Once the disjunction is achieved the appliance must be held in place for several months until the median palatine suture has grown in.

The quad helix was designed by Ricketts. As its name suggests, it is a transpalatine arc made of .032 Blue Elgiloy with four loops to increase its elasticity. It can produce both an alveolar expansion and a slow maxillary disjunction.

Maxillary expansion frees the condyles of all strain due to a non-physiological occlusion in the maximum contact position secondary to a functional lateral mandibular deviation. It also allows improvement of breathing and correction of a Class 2 malocclusion by correcting the rotation of the maxillary molars. 

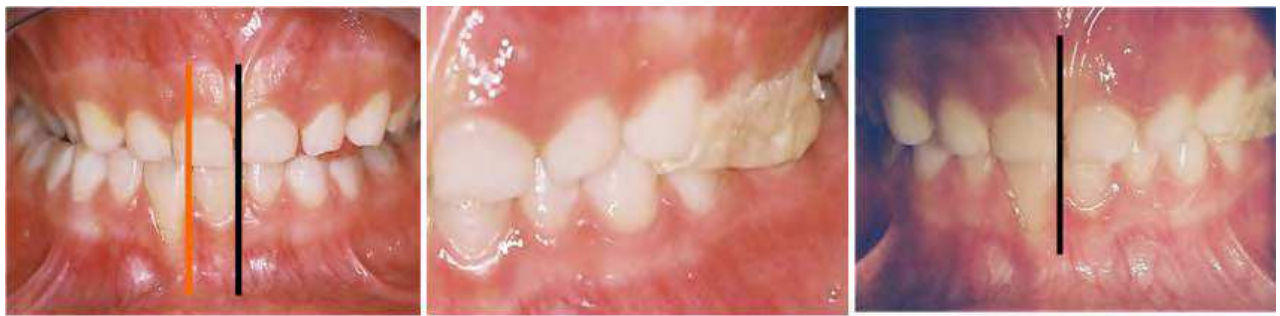

Case 9. Interceptive treatment of a right mandibular lateral deviation by resin direct tracks
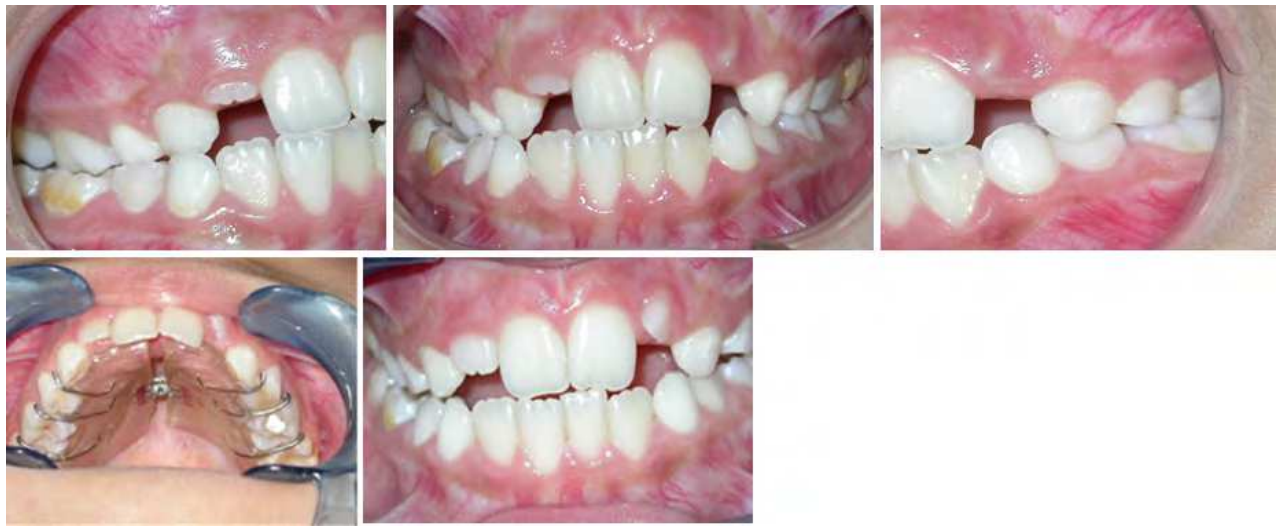

Case 10. Interceptive treatment of a mandibular lateral right deviation following a bilateral maxillary endoalveolitis by maxillary expansion using a median screw expander
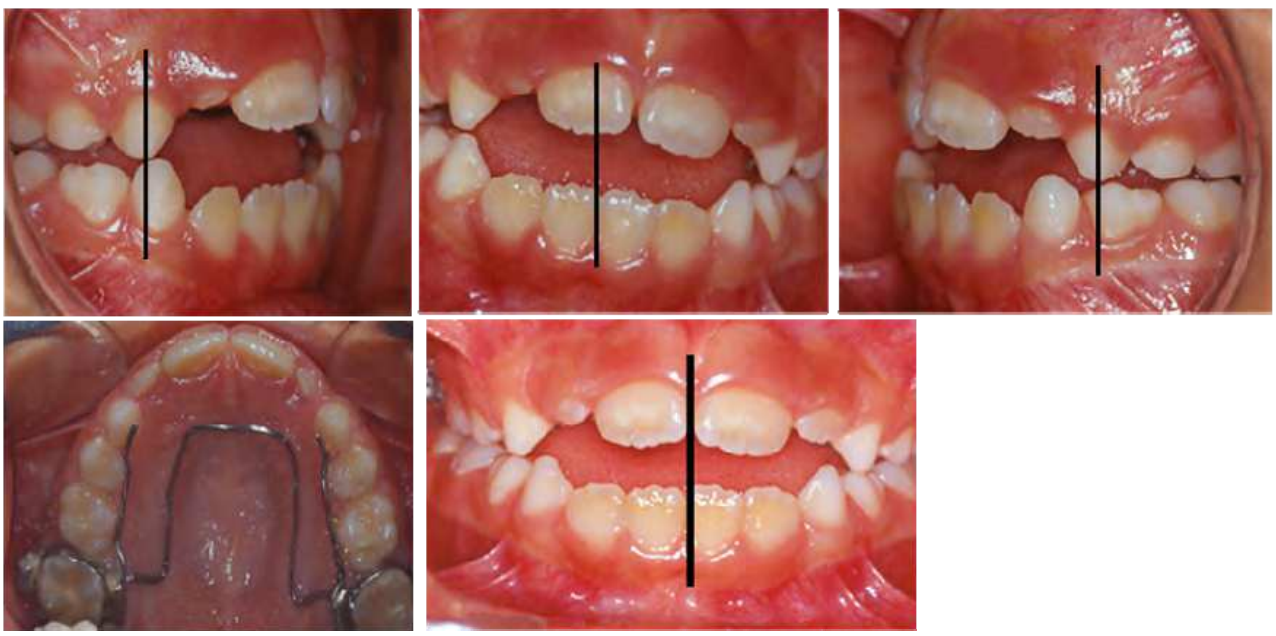

Case 11. Interceptive treatment of a mandibular lateral right deviation following a bilateral maxillary endoalveolitis by maxillary expansion using a quad helix 

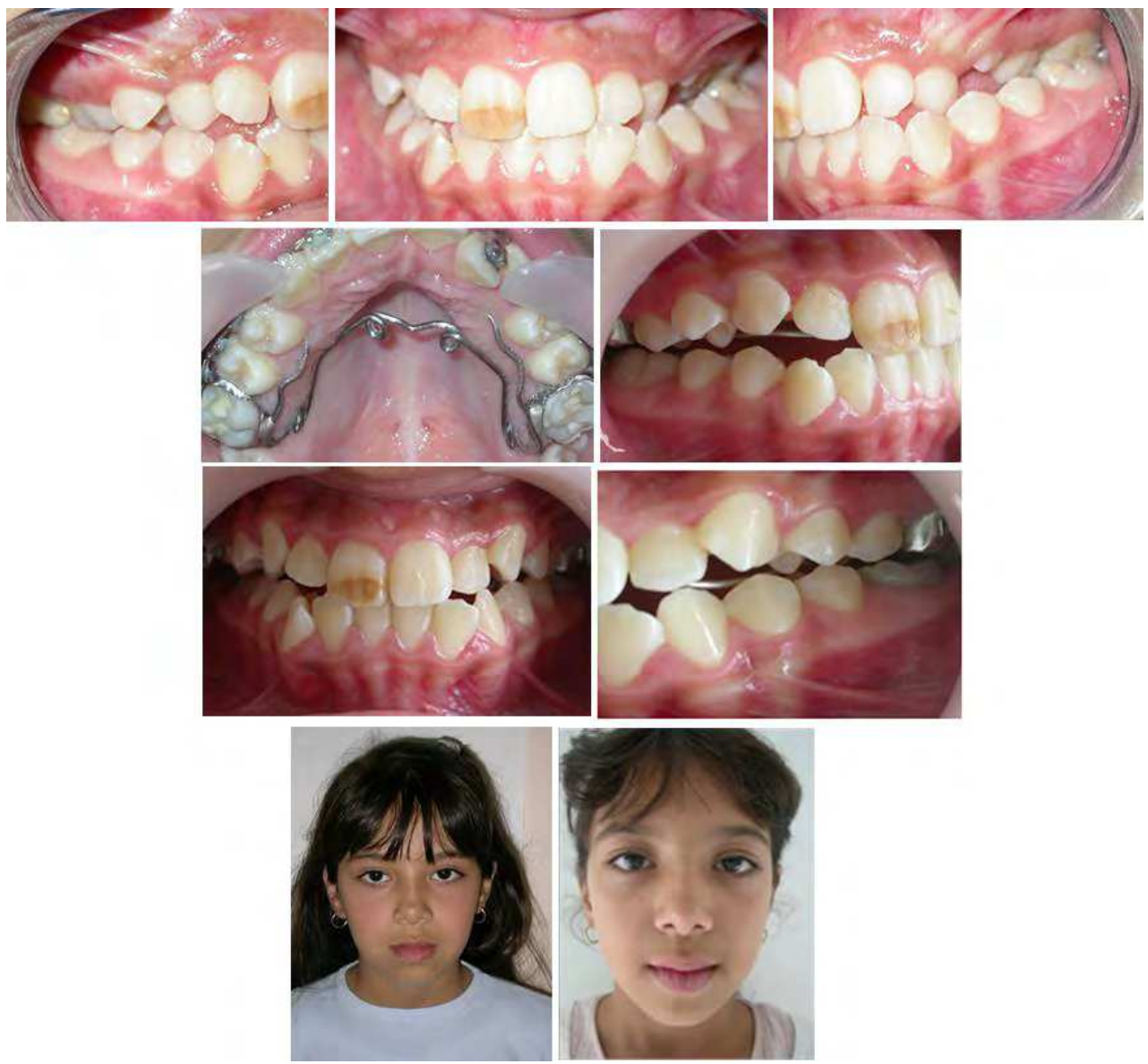

Case 12. Interceptive treatment of a mandibular lateral right deviation following a bilateral maxillary endoalveolitis by maxillary expansion using a quad helix

\subsection{Early treatment of anterior open bites}

These disorders are defined as an insufficient vertical development of the anterior alveolar processes (SUBTENLY \& SAKUDA 1964). KELLY et al. (1973) have reported a prevalence of 3.5\% in Caucasian American children and 16.5\% among Afro-Americans. PROFFIT et al. (1988) report a prevalence of approximately 3.5\% in patients aged 8 to 17 years. Anterior open bites can be of skeletal origin, linked to a hyperdivergent facial typology (TOLLARO 1983, RICHARDSON 1981), but are often functional in origin. Mouth breathing, atypical swallowing by tongue-thrusting and thumbsucking are the main aetiologies (SASSOUNI 1969, NGAN 1997, TULLEY 1972, STRAUB 1962). Hence it is mandatory to correct these dysfunctions as early as possible to remove the obstacle to vertical alveolar growth: this sometimes leads to spontaneous correction of the gap (BASCIFTCI 2002). Lingual re-education will be both active, through swallowing exercises that the child will be asked to perform regularly, and passive, by the fitting of a tongue repositioning appliance 
such as the nocturnal tongue envelope of BRUNO BONNET (Case 14) or a thumb guard to prevent thumbsucking (Case 15).

The planned outcome will be achieved in 4-8 months if the child cooperates.

A systematic review by PARLA COZZA et al. (2005) shows that early treatment of anterior gaps intercepts the malocclusion and reduces the need for treatment during adolescence (Case 13).
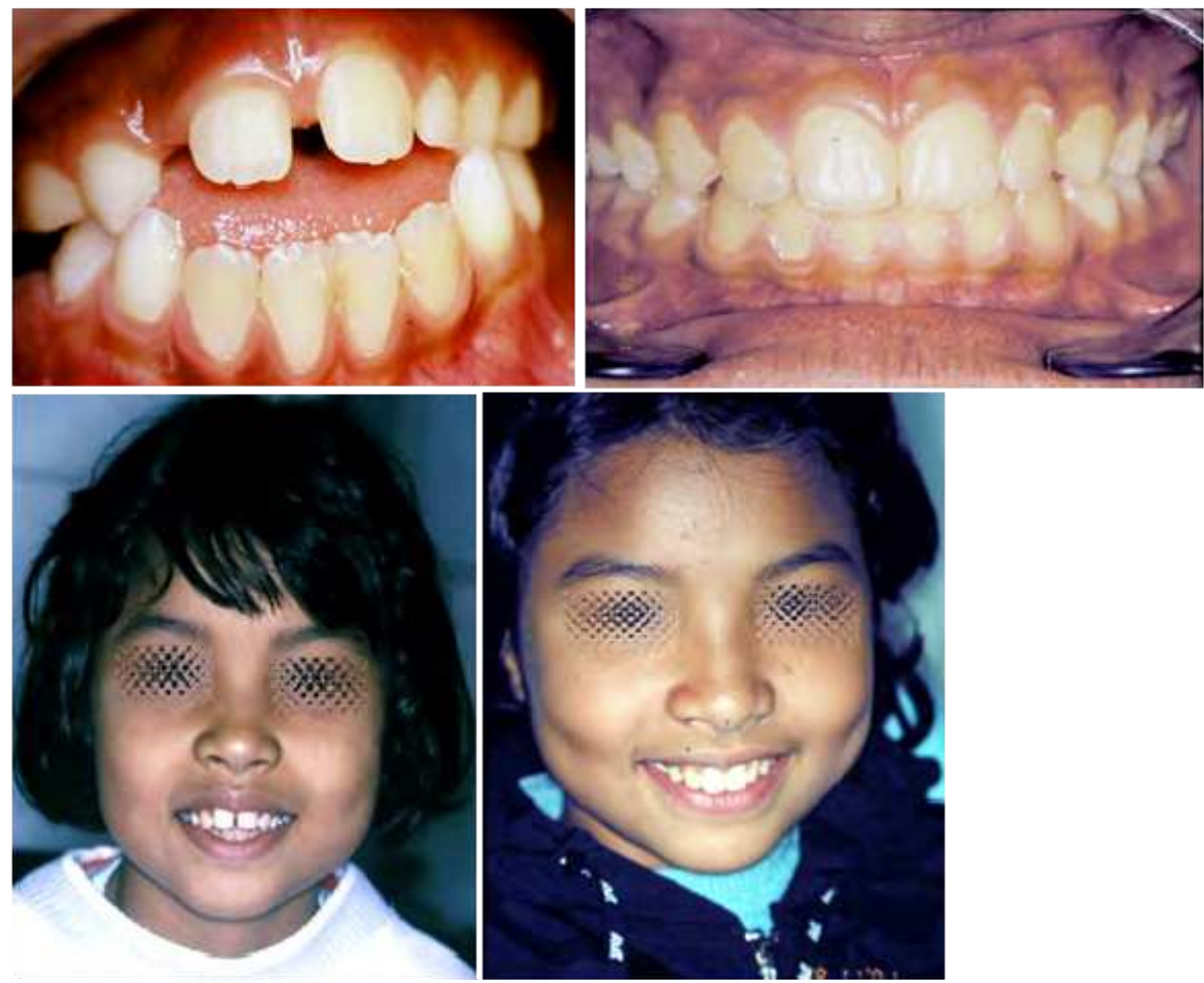

Case 13. Functional treatment of anterior open bite 

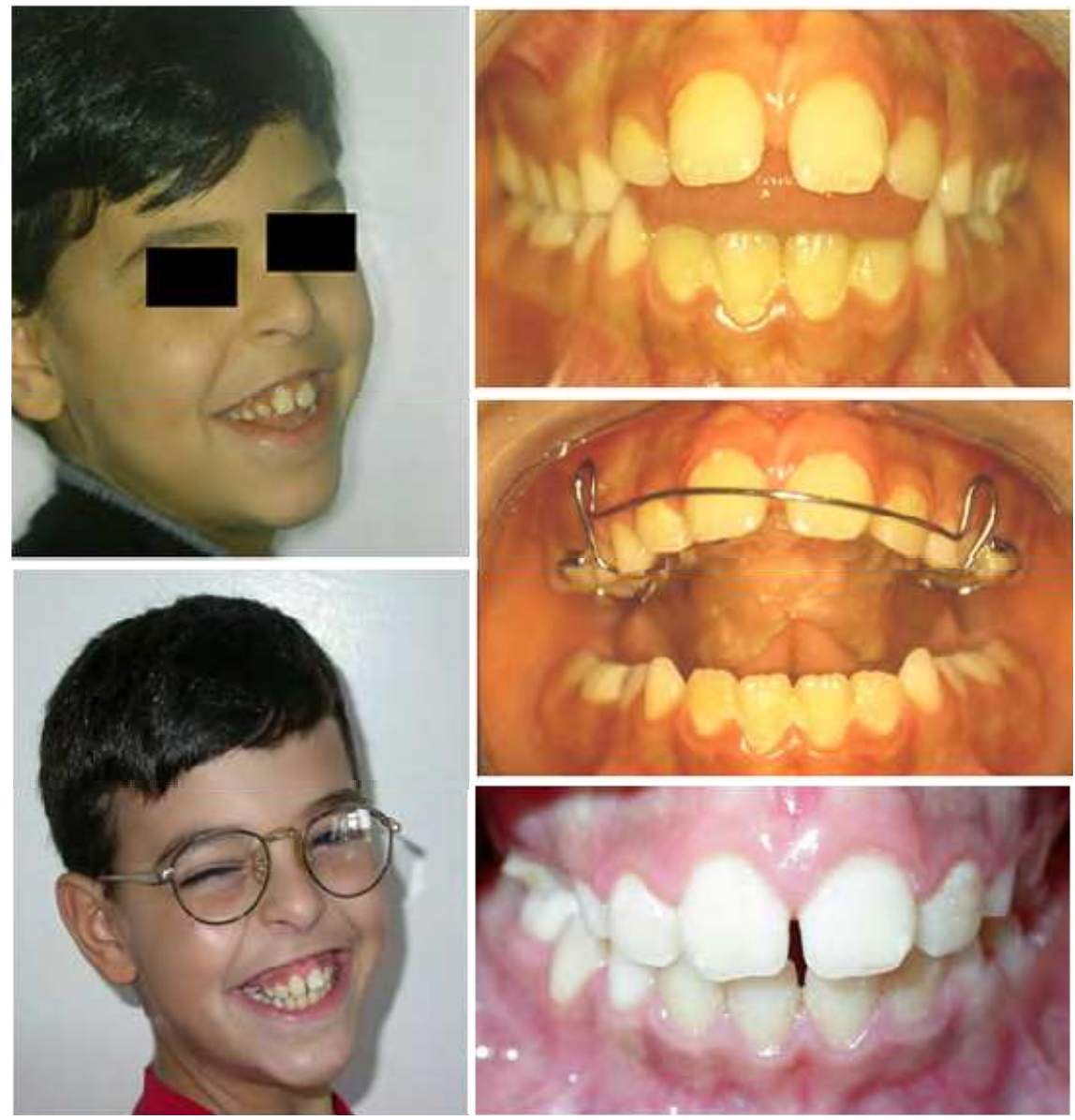

Case 14. Functional treatment of anterior open bite by the nocturnal tongue envelope 


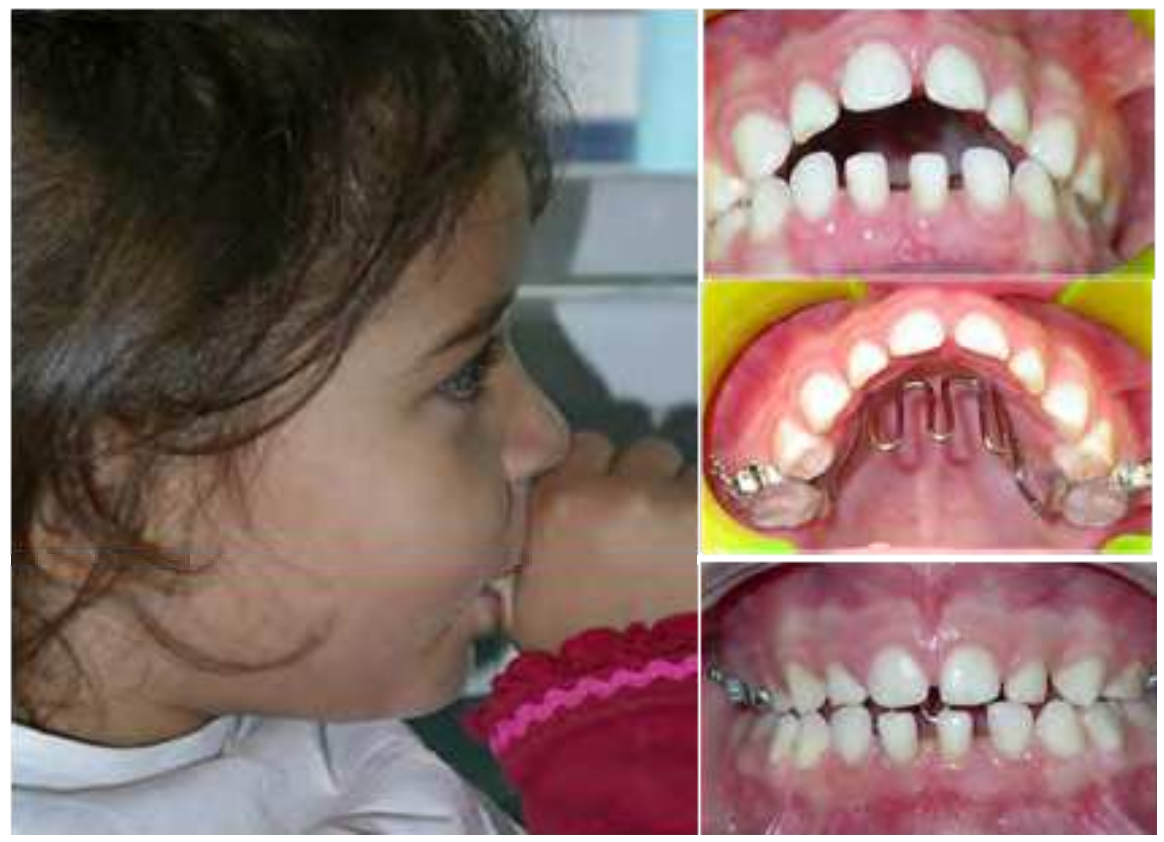

Case 15. Functional treatment of anterior open bite secondary to thumb sucking by a thumb guard

\subsection{Early treatment of class II abnormalities}

Skeletal Class II abnormalities are defined as those in which the maxilla is overhung relative to the mandible. They can be of maxillary, mandibular or mixed origin.

In children, Class II abnormalities are often due to locked mandibular growth. GUGINO describes three types of lock: functional, mechanical and psychological. Incisor overjet, a transverse deficit of the maxillary arch, and a distopalatine rotation of the maxillary molars are examples of mechanical locks that give the mandible a permanent retroposition.

It is thus important to remove these locks early on to permit free mandibular growth. This is the concept of unlocking developed by the bioprogressive school of Ricketts.

To address hereditary forms (maxillary overjet or mandibular underjet), early treatment consists is fitting an activator of mandibular growth sometimes associated with an extraoral force.

Two facts justify early care for Class II abnormalities. The first is that the tissues of the craniofacial complex tend to respond more readily in young subjects. The second is that young patients cooperate better than older ones (KING, 1989). Several studies have shown that the best age for patient cooperation is preadolescence (ELDER 1974, DROSCHL 1973).

For mixed dentition the correction of molar rotations will be performed using a quad helix or a palatine rod.

Incisor overbite can be reduced by a Ricketts basal arch. This is a device made of $.016 \times .016$ Blue Elgiloy wire fixed to bands fitted on the first permanent molars and on brackets cemented to incisors (Cases 16 and 17). 
There are several types of mandibular growth activators, e.g. ROBIN's monobloc, FRANKEL's function regulator, BALTERS' Bionator and the HERBST apparatus. All place the mandible in a propulsive position by activating the mandibular propulsors, and in particular the lateral pterygoid muscle. These form the functional matrix of the condylar cartilage, itself the main centre of mandibular growth, as shown by the work of MOSS and PETROVIC (Case 18).

However, this mandibular response secondary to the activators remains controversial: some see an orthopaedic effect, while others find merely an alveolodental effect. Animal trials have shown that extraoral forces (ELDER 1974, DROSCHL1973) and functional orthopaedic appliances (McNAMARA 1973, STOCKLI 1971) cause significant modifications to craniofacial growth. These findings are supported by others on humans using activators (DEMISCH 1972, FREUNTHALLER 1967) or FRANKEL's functional regulator (RIGHELLIS 1983, McNAMARA 1985), which have shown a significant increase in mandibular growth. Other clinical studies (BAUMRIND 1983, KING 1957) have shown that extraoral forces applied to the maxilla cause a slowing of maxillary forward growth. Other authors have even found extraoral forces to cause a rearward, downward repositioning of the maxillary complex (WATSON 1972,WIESLANDER 1963, POULTON 1967).

AMSTRONG (1971) has described a rapid correction of Class II abnormalities par light extraoral forces parallel to the occlusion plane in growing children. However, we must bear in mind that these skeletal effects are always accompanied by alveolodental effects. GIANELLY (38 in 5) concluded that the main alveolodental effect of Class II orthopaedic procedures was egression and distalisation of the maxillary molars and mesialisation of the mandibular dentition.

The benefits of early treatment of Class II abnormalities are numerous: e.g. the prevention of trauma to the maxillary incisors by overcorrection of overhang (KREIT 1968, O'MULLANE 1973), the interception of worsening malocclusion, and better psychological and social integration of the child. It has also been reported that the correction of Class II malocclusions improves orofacial functions (JANSON \& HASUND 1981, WIGDOROWICSMAKOWEROWA 1979).
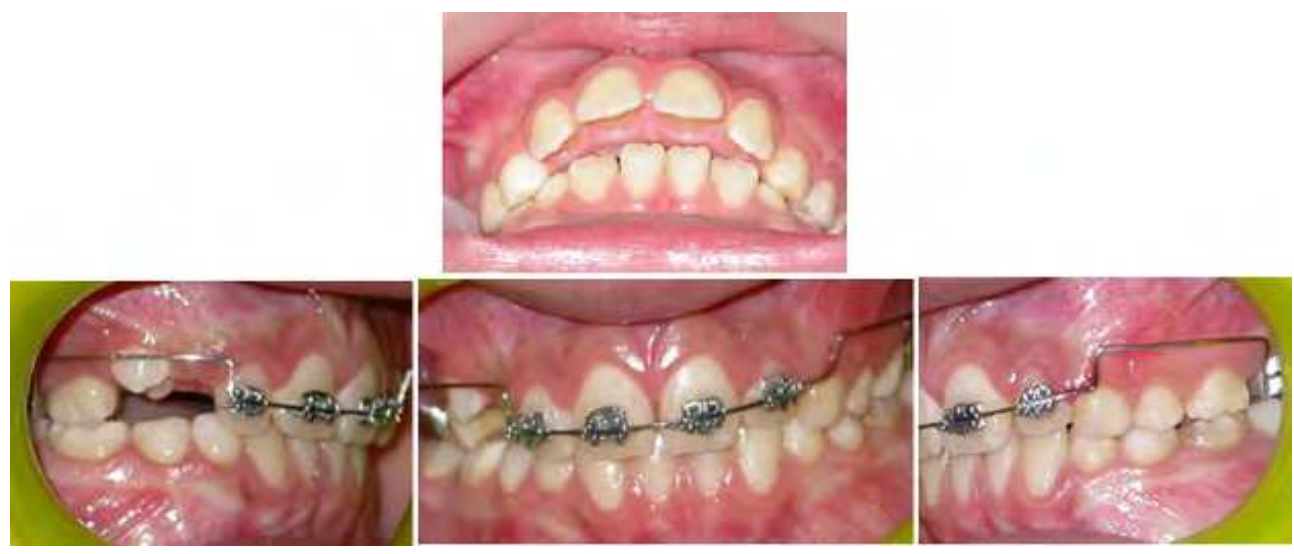

Case 16. Release of mandibular growth by raising over bite with a Ricketts basal arch 

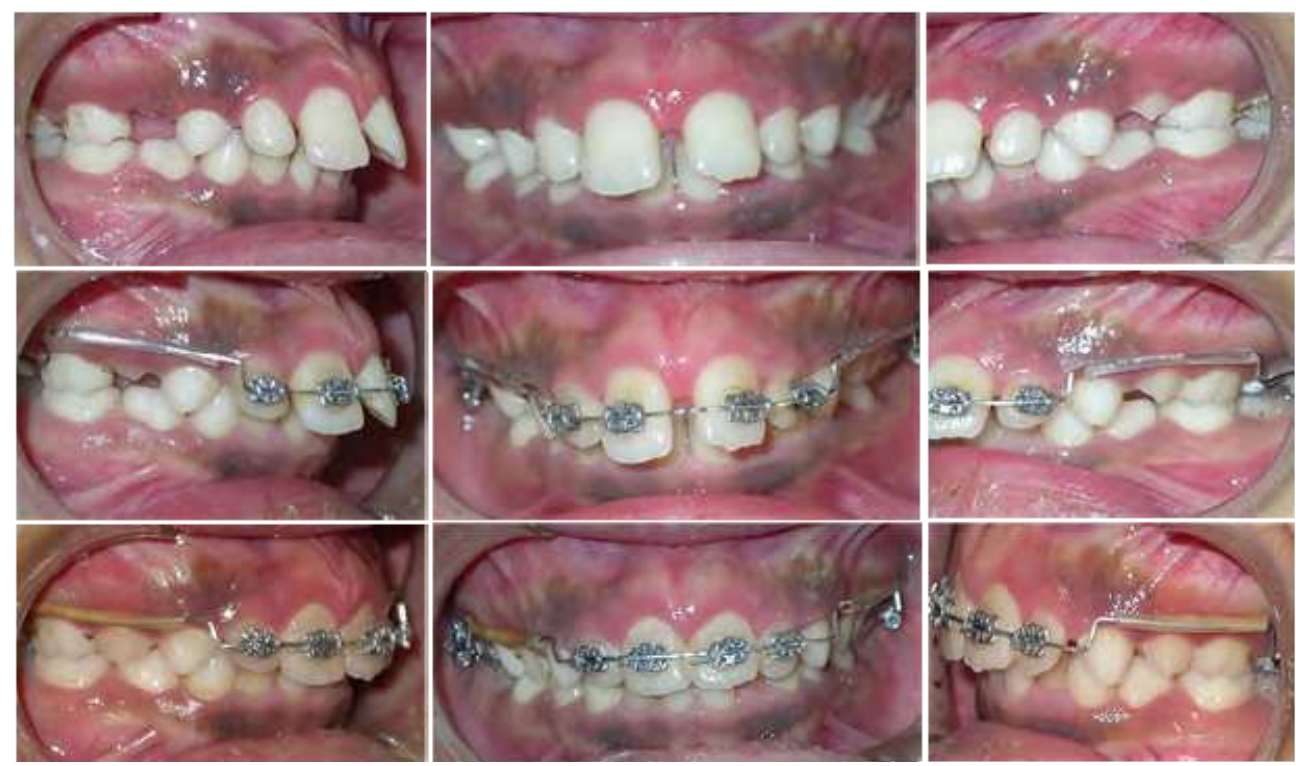

Case17. Ricketts basal arch as interceptive treatment of overbite

\subsection{Early treatment of skeletal class III abnormalities}

Class III malocclusions are syndromic: the discrepancy between the maxilla and the mandible has many anatomical expressions. The most frequent abnormality is maxillary retrognathy and not, as often thought, mandibular prognathy. There seems to be a consensus concerning the utility of early treatment of skeletal Class III disorders.

The treatment of Class III abnormalities is straightforward, and is more efficacious if applied early, on deciduous dentition before age 6 years. This therapy undertaken early induces a new maxillary growth. The maxilla, repositioned correctly, grows together with the mandible (KAPSUT 1998, MACNAMARA 1987, NGAN1998, TORRES 2000)

The work of DELAIRE and co-workers, initiated 30 years ago, has allowed great strides in the treatment of Class III malocclusions, in particular through the use of a facial mask. Today it is generally acknowledged that the treatment of Class III malocclusions should preferably be orthopaedic and early. The interceptive treatment should be applied as early as possible; the rate of mandibular growth is the factor that guides the choice of therapeutic procedures.

These early treatments are useful for the forward shift of the mandible through the elimination of its aetiology, which can be functional or occlusal. The correction of the anterior or lateral crossbite lies within the scope of interceptive treatment of mandibular forward shift. They are also useful for Class III malocclusions due to maxillary underjet. DELAIRE's face mask is the main appliance used.

\subsubsection{Justification for early treatment of class III abnormalities}

We know that one of the most important factors in maxillary growth is the mandibular stroke: it is this hammer and anvil movement that causes the maxilla to develop. If there is a 

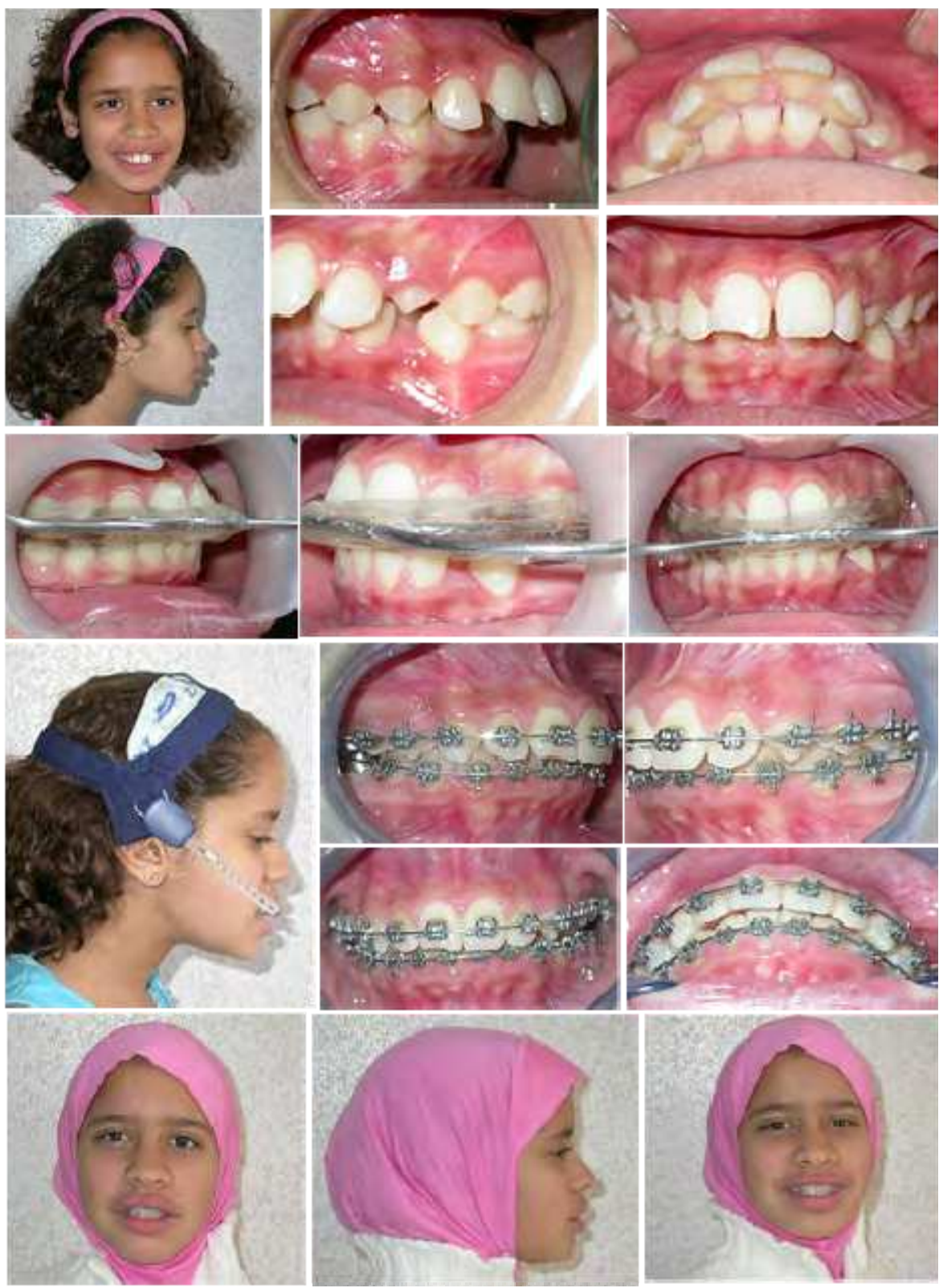

Case 18. Treatment in two phases of a skeletal Class II malocclusion

reversed incisor occlusion, then the maxillary growth is insufficiently elicited; the maxilla will stop growing while the mandible continues to develop regardless of the maxilla. It is thus necessary to establish the secant function of the incisors. This normalisation enables lateral movements that restore masticatory function. In addition, the early 
intervention of the practitioner induces a change in the angulation of the base of the skull, increasing the sphenoid angle and developing the anterior frontal part. It is possible to bring forward the implantation of the upper end of the maxilla to some extent. This was demonstrated by both DELAIRE and DESHAYES.

MCNAMARA (1987) found the result to be "engrammed in the new growth". We believe this to be true insofar as the treatment is applied early. LOREILLE confirmed this, finding that it was clearly possible to act on the causes of a great many facial dysmorphisms, provided early treatment could act on the causes of impaired growth.

In the literature, all the authors who have shown an interest in the treatment of Class III disorders emphasise the importance of early treatment (SAKAMOTO 1981, SUGWARA 1990, GRABER \& PROFITT 2007). MCNAMARA (1993) justifies early intervention with the orthopaedic mask by pointing out that as the patient is young, the results of the treatment by facial mask are subsequently incorporated in future growth. BACETTI (1998) et al. claim that early treatment is more efficacious when applied to deciduous than to mixed dentition. For DESHAYES, the best time to apply an orthopaedic treatment, with lasting results and no relapse, is while the telencephalon is still very actively growing (i.e. before age 6 years).

\subsubsection{Preventive treatment}

Functional re-education is the first interceptive preventive component of Class III malocclusions. It is necessary to re-educate breathing and tongue posture through active and passive re-education.

The tongue is not the only factor responsible for maxillary hypodevelopment, and rehabilitation of bilateral mastication has also to be integrated into the therapy. Professor Planas must have been the first to demonstrate that the narrowness of the maxilla, which favours unilateral mastication, has an influence not only on the maxilla but also on mandibular symmetry. Accordingly, selective impressions are made from the deciduous dentition: these impressions are used for selective guidance and unlocking, and give excellent results. For Planas, they form the basis of a neuro-occlusal rehabilitation therapy.

In Class III abnormalities of maxillary origin, maxillary retrognathy is often accompanied by endognathy. To address this, several appliances can be used such as the quad helix and the palatine expander. Disjunction in the transverse direction allows a widening of the bone base and the floor of the nasal cavity. It thus favours mouth breathing and pushes out the insertions the buccinator. In the anteroposterior direction the SNA angle is increased by 0$25^{\circ}$. In the vertical direction there is an upward movement of point $\mathrm{N}$ and a downward movement of points A and ENA.

The anteroposterior relations of the dental arches can also be corrected using Planas direct tracks, which allow an end-to-end occlusion to be obtained and all occlusal obstacles to be removed so that the mandible resumes it usual normal low amplitude excursions. Their action is based on the 'minimum height laws'. The tracks are inclined planes $4 \mathrm{~mm}$ wide located just on the lingual face of the dental arches, thus preventing tongue interposition.

A removable Hawley plate fitted with a simple cantilever spring made of $0.6 \mathrm{~mm}$ wire can be used to vestibulate the upper incisors. (Cases 19 and 21)

The anterior inclined plane: here is a resin or composite brace cemented to the lower incisors with a tooled inclined plane opposite the teeth in a reversed bite translating the muscle forces into mechanical forces to correct the bite. (Case 20)

Elastic bands for crossbite occlusion: they are used to displace the bite from one tooth or group of teeth. Multiband treatment can also be applied to vestibulate the upper incisors and so correct the incisor bite. (Case 22) 
Two-band device: this is a bihelix acting on the sagittal plane to vestibulate the upper incisors, with two lateral loops. The opening of the loops causes a vestibular tilting of the upper incisors.

Occlusal elevator wedges: these are bonded onto the occlusal surfaces of the deciduous maxillary molars. The height of the composites is adjusted for centred occlusion and set so as to obtain an anterior occlusion of about $1 \mathrm{~mm}$. The tongue, by centrifugal pressure, brings the incisors naturally into the correct position.
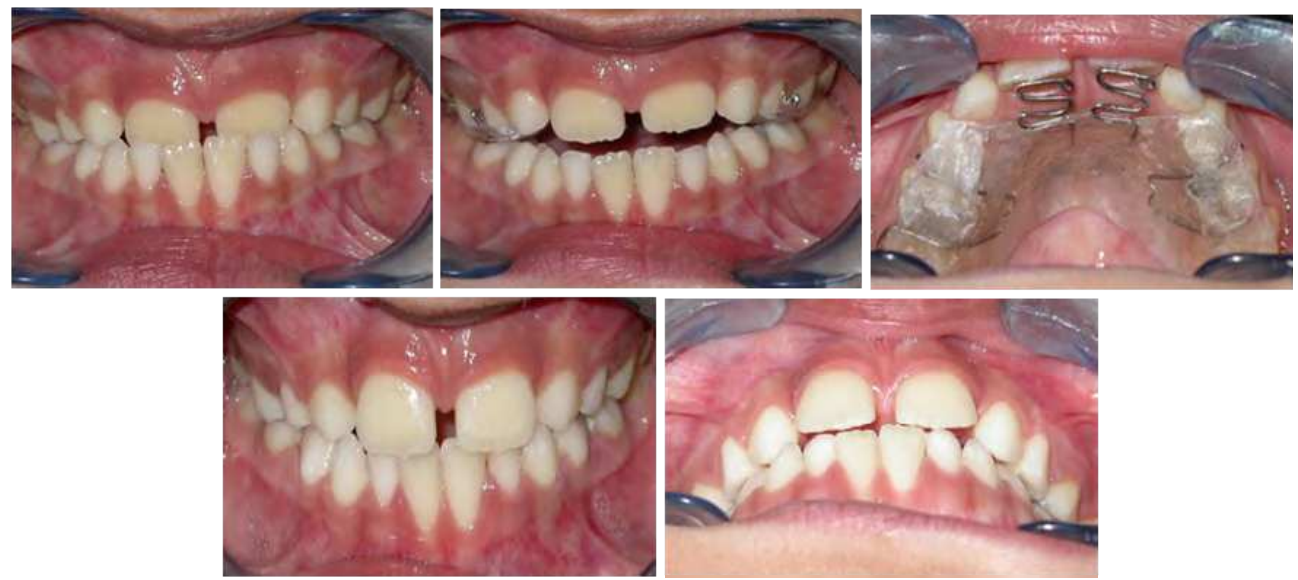

Case 19. Early correction of anterior crossbite with a removable Hawley plate fitted with a simple cantilever spring
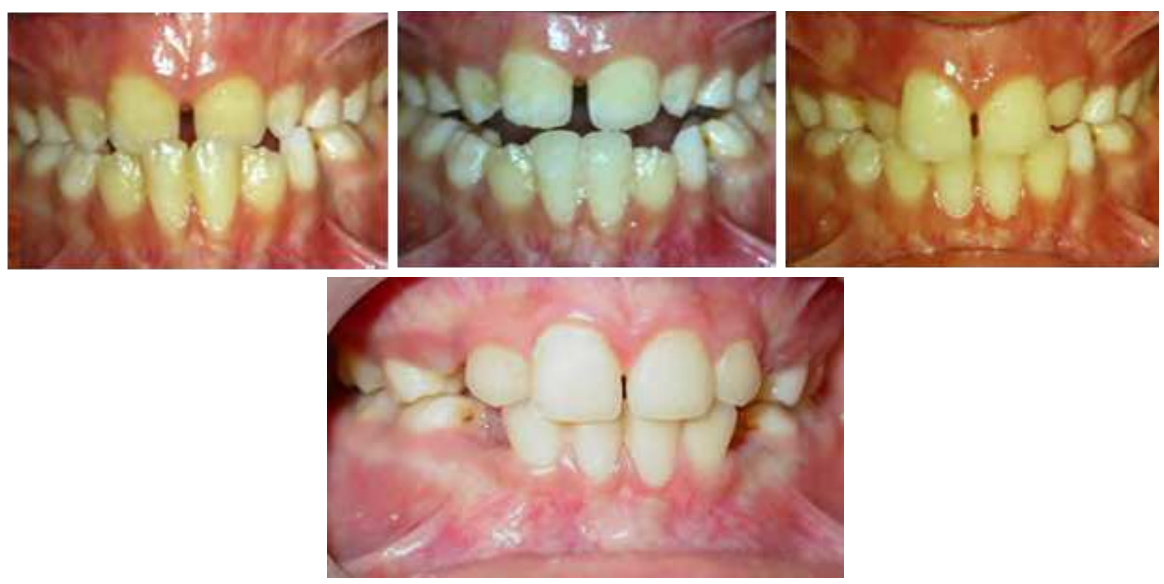

Case 20. Early correction of anterior crossbite withanterior composite inclined plane 


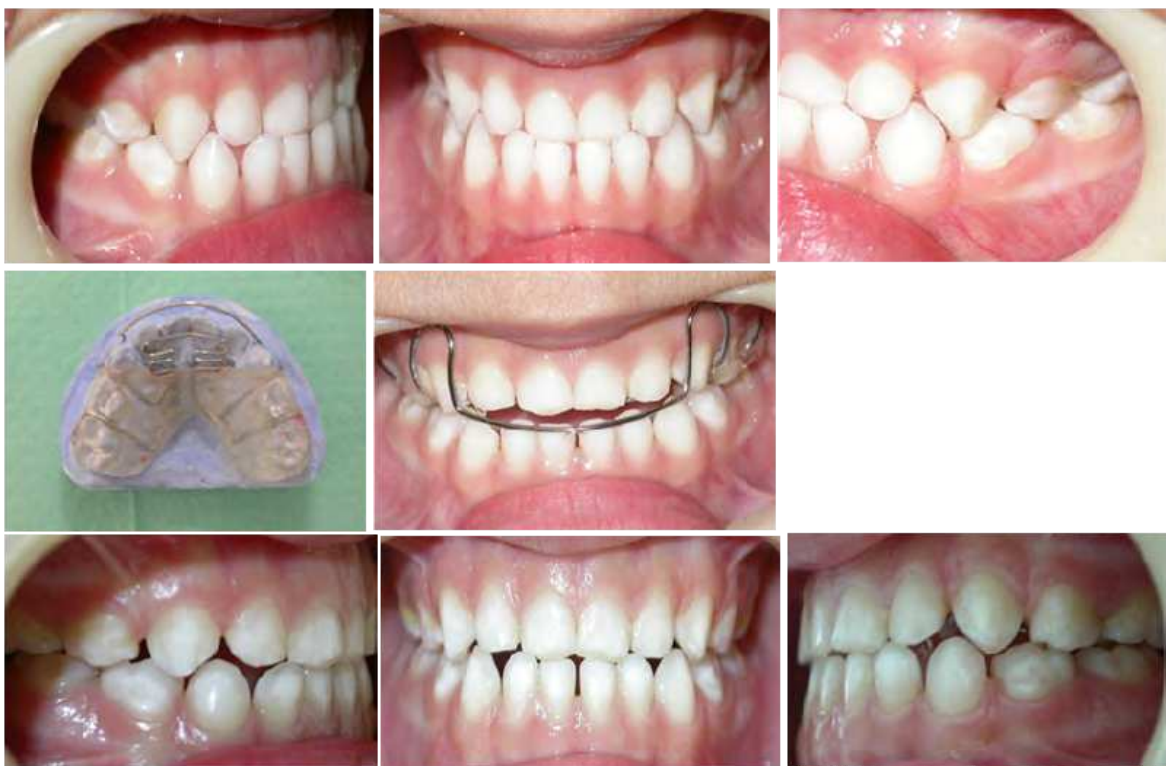

Case 21. Early correction of anterior crossbite with a removable Hawley plate fitted with a simple cantilever spring
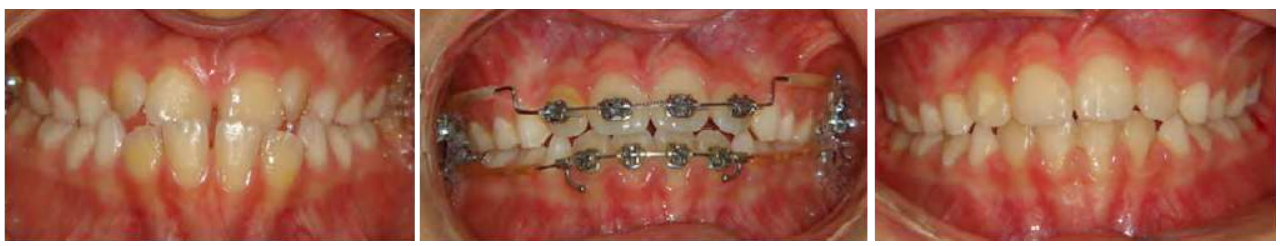

Case 22. Multiband treatment to vestibulate the upper incisors and to correct the incisor bite

\subsubsection{Orthopaedic treatment of class III abnormalities}

In the presence of a sagittal skeletal disharmony, only the orthopaedic approach will yield a satisfactory result that is stable in the long term. Successful use of maxillary protraction appliances in the treatment of skeletal Class III cases attributable to maxillary retrognathy has been reported in many studies.

DELAIRE's face mask (1971)

In most cases this is the therapy of choice for Class III disorders. The method was described by DELAIRE (1971) and thoroughly codified by Verdon and SALAGNAK.

A review of the different orthodontic textbooks: CHATEAU, BASSIGNY, MCNAMARA, PROFITT, GRABER, etc. confirms the utility of this therapy, while at the same time detailing the different indications.

The treatment consists in applying a posteroanterior orthopaedic force on an anterior facial location through elastic bands connected to an intrabuccal appliance (Cases 23, 24 and 25) DELAIRE's face mask is composed of an external appliance and an intrabuccal device. There are several types of orthopaedic mask: the most classical type has a forehead support connected to a chincap by metal rods. At the level of the commissural line is welded a hoop 
to attach the elastic bands. If necessary, the forehead support can be custom-shaped to the child's forehead. Adolescents seem to prefer another type of protraction mask, the Petit model, which is less bulky with a mid-positioned bar, which replaces the support frame. The intrabuccal device can be either of the following:

- A double arch: this is made of two very stiff 10/10 arches welded onto two molar bands. The palatine arch is adjusted to the tooth necks. The vestibular arch must be placed at least $1 \mathrm{~mm}$ in front of the vestibular surface of the teeth to allow the premaxilla to expand.

- Plate or cemented brace: the cemented brace method described by Amoric has the advantage being rapid, given the removal of the occlusal interference, but also the disadvantage of cementing, with attendant risk for dental tissue.

Elastic bands are stretched on each side to balance the forces. Traction must always be oblique, downwards and forwards.

The maxillary shift must always be overcorrected by a few millimetres.

The modifications observed using this type of appliance reported by BACCETTI, 1998 comprise:

- Maxilla: a change in the orientation of the maxilla relative to the base of the skull, an increase in the length of the upper alveolar area and an average increase in the ENAENP distance of $3 \mathrm{~mm}$.

- Mandible: a rearward and downward shift of the mandible, and closing of the goniac angle.

- Occlusion: a modification of the tooth contact and of the orientation of the occlusal plane, which is rotated anteriorly.

- Profile: an improved interlabial contact.

These immediate modifications have an impact on the labial, lingual, masticatory and occlusal functions, etc., which in turn progressively and favourably modify the facial skeleton.

We also point out that the association of the facial mask with maxillary disjunction proves more efficacious (GUYER 1986, NARTALLO-TURLEY 1992).

\section{Activators}

An activator is a removable device that uses intrinsic forces (orofacial muscles) to correct sagittal discrepancies. Class III abnormalities that are chiefly due to functional problems enjoy a favourable prognosis when such activators are used provided they are associated with functional re-education of the tongue and respiratory functions.

The mandible is brought into a more rearward position, as the appliance is fixed to the maxillary arch; the mandible pushes the maxilla forward. The anterior guide is thereby modified; we generally see a mandibular plicature and a closing of the goniac angle, together with a 'verticalisation' of growth and a slight overall posterior rotation.

To conclude, we can assert that early orthodontic treatment is the key to successful, straightforward treatment of Class II malocclusion. It must be undertaken as early as possible, as soon as the child is seen in consultation.

This will ensure that it gives best results, which are most often spectacular.

There is much theory here, although it is backed by large amounts of practice. However, the child's developing personality and capabilities must once more become central: early treatment of Class III abnormalities will ensure the child enjoys a better social integration.

We can sum up by quoting the judicious advice of Dr Marc Vesse: 'Opt for early treatment: your young patientswill thank you and so will their parents'. 


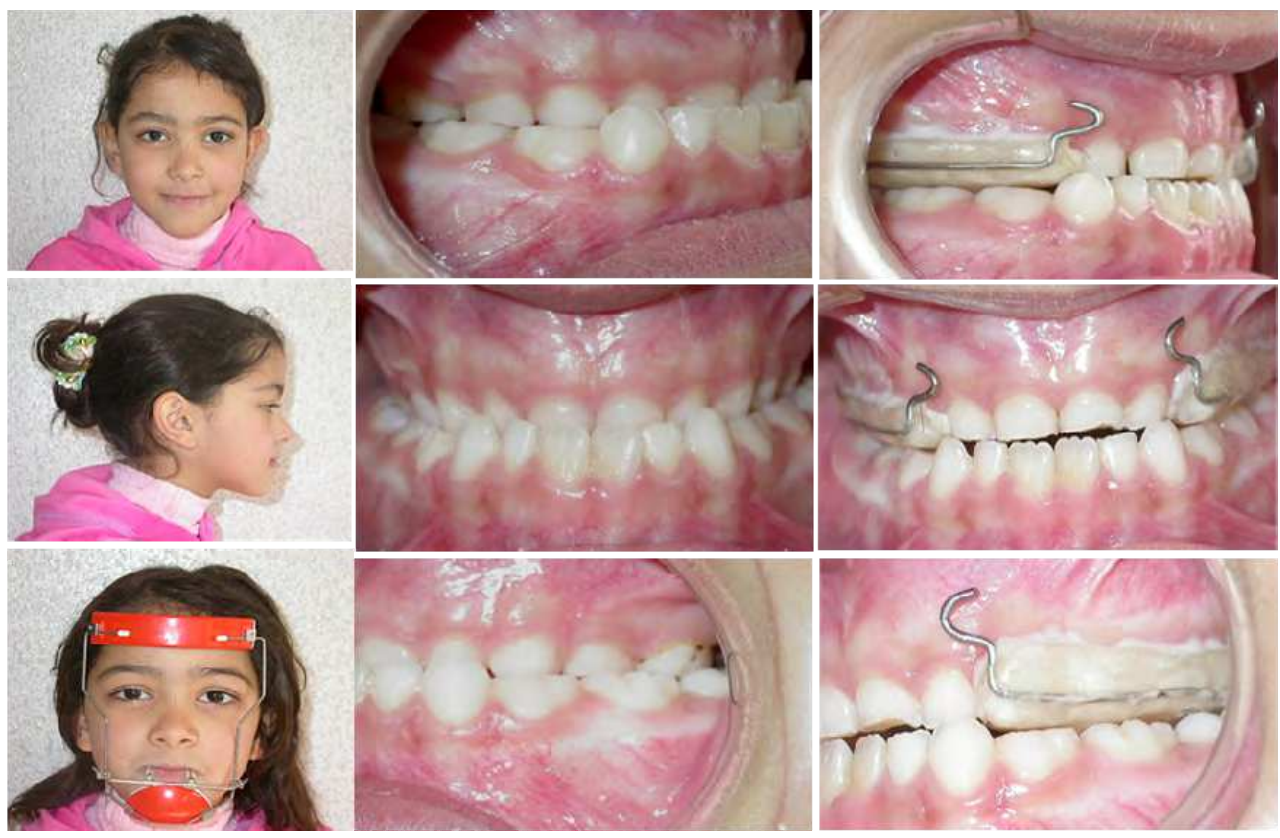

Case 23. Early treatment of skeletal Class III cases attributable to maxillary retrognathy with a DELAIRE's face mask 

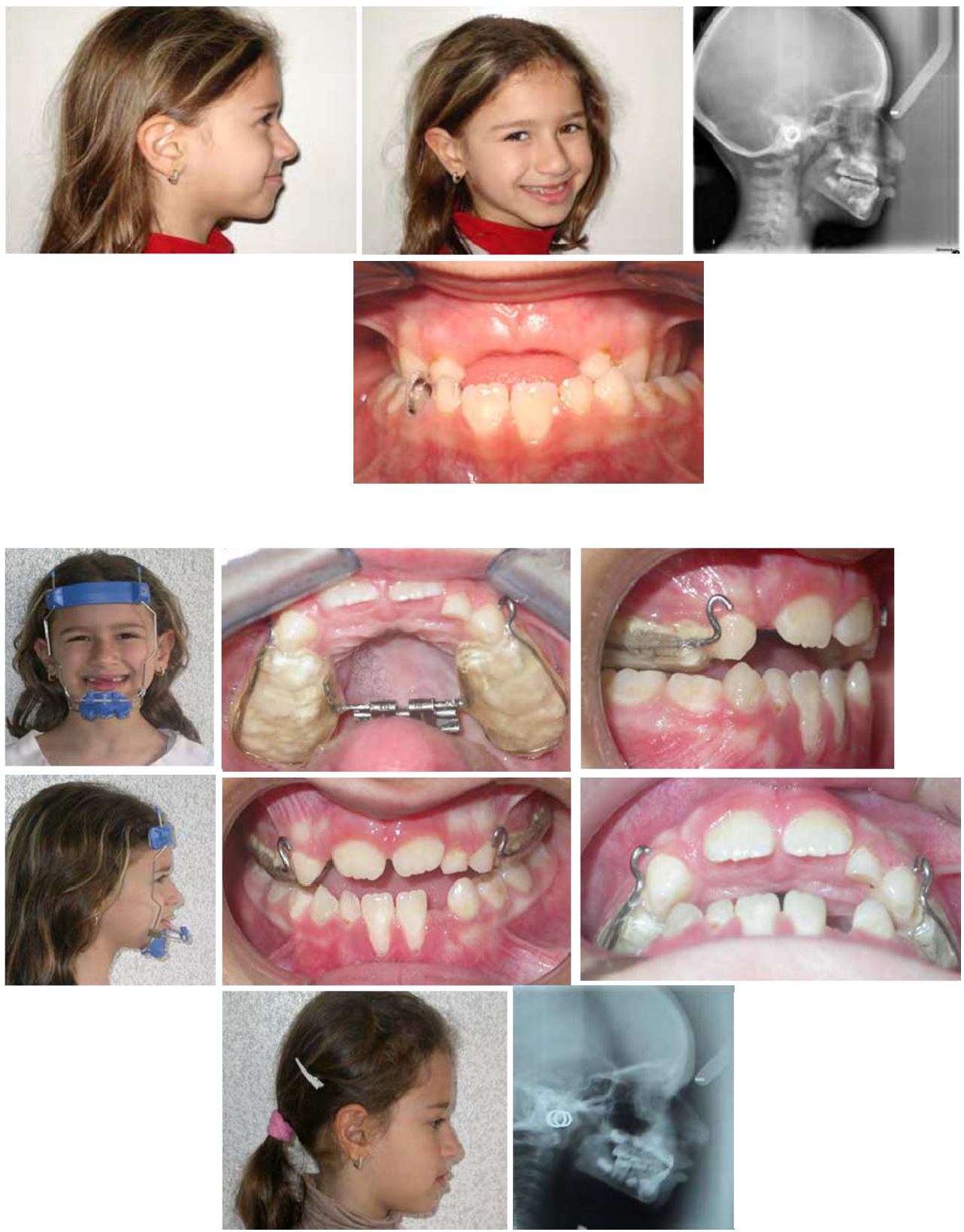

Case 24. Early treatment of skeletal Class III with a DELAIRE's face mask 

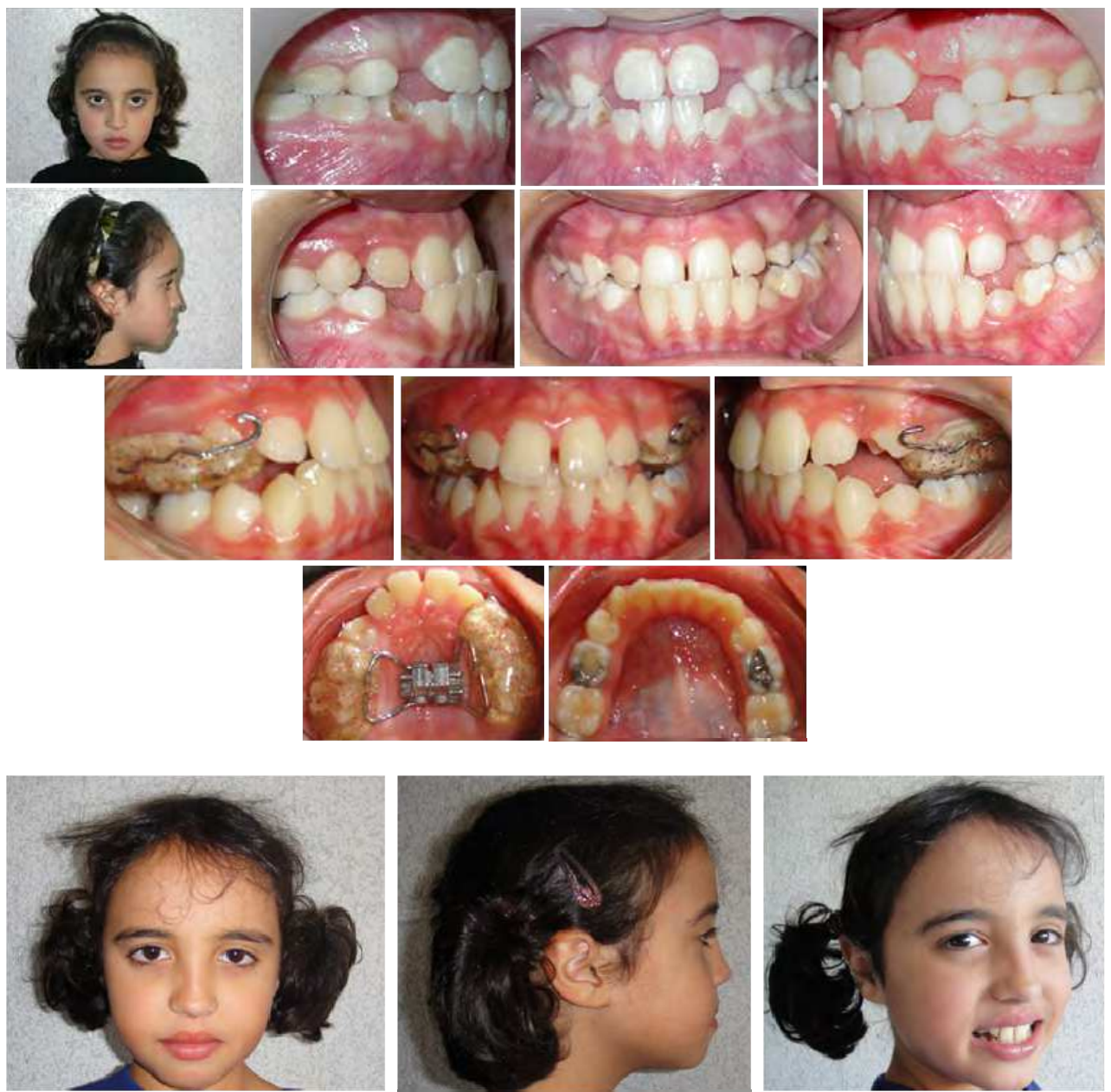

Case 25. DELAIRE's face mask to treat a skeletal Cl III

\section{Conclusion}

Early treatment orthodontic procedures are relatively simple and inexpensive treatment approaches that target developing malocclusions during the mixed or deciduous dention. Orthodontists perceive these as useful ways to reduce the severity of malocclusions, improve a patient's self image, eliminate destructive habits, facilitate normal tooth eruption, and improve some growth patterns. (GREGORY KING 2010)

Early treatments in orthodontics do not produce finished orthodontic results without a second phase of treatment in the permanent dentition. But several studies have suggested that systematically planned interceptive treatment in the mixed dentition might contribute to a significant reduction in treatment need between the ages of 8 and 12 years, often producing results so that further need can be categorized as elective. 


\section{References}

Armstrong MM.(1971): Controlling the magnitude, direction, and duration of extraoral force. Am J Orthod.,Vol.59, N³, pp:217-43.

Baccetti T,and al.(1998) : Skeletal effects of early treatment of Class III malocclusion with maxillary expansion and face-mask therapy. Am J Orthod Dentofacial Orthop. Vol.113, N³, pp:333-43.

Basciftci FA, Karaman AI.(2002) :Effects of a modified acrylic bonded rapid maxillary expansion appliance and vertical chin cap on dentofacial structures. Angle Orthod.Vol.72, N¹, p:61-71.

Baumrind S, and al. (1983) :Superimpositional assessment of treatment-associated changes in the temporomandibular joint and the mandibular symphysis. Am J Orthod. Vol.84, N6, pp:443-65.

Behlfelt K, and al (1989) : Dentition in children with enlarged tonsils compared to control children. Eur J Orthod, Vol 11, N4, pp:416-29.

Clifford FO. (1971): Cross-bite correction in the deciduous dentition: principles and procedures. Am J Ortthod.Vol.59:343-9

Cozza P and al. (2005) : Early orthodontic treatment of skeletal open-bite malocclusion: a systematic review.Angle Orthod.Vol.75, N5, pp:707-13.

Dale JG. (2000) Serial extraction ... nobody does that anymore. Am J Orthod Dentofacial Orthop.Vol.117, N5, pp:564-6.

Delaire J.(1971) Confection du masque ortopédique. Rev Stomat Paris Vol.72, pp: 579- 84

Demisch A.(1972):: Effects of activator therapy on the craniofacial skeleton in classe II, division 1 malocclusion. Trans. Eur. Orthod. Soc.,pp :295-310.

Droschl H.(1973): The effect of heavy orthopedic forces on the maxilla in the growing Saimiri sciureus. Am J Orthod Dentofacial Orthop., Vol.63, pp:449-61

Elder JR., Tuenge,RJ. (1974) : Cephalometric and histologic changes produced by extra-oral high pull traction of the maxilla of macaca Mulatta. Am J Orthod Dentofacial Orthop.Vol.66, pp:599-617.

Egermark-Eriksson I, and al.(1990) :A longitudinal study on malocclusion in relation to signs and symptoms of cranio-mandibular disorders in children and adolescents. Eur J OrthodVol.12, N4, pp:399-407.

Freunthaller P.(1967): Cephalometric observation in Class II, Division I malocclusions treated with the activator. Angle Orthod.Vol.37, №1, pp:18-25.

Gugino CF, Dus I. (1998) :Unlocking orthodontic malocclusions: an interplay between form and function.Semin Orthod. Vol.4, N44, pp:246-55.

Ghafari J, and al. (1998) : Headgear versus function regulator in the early treatment of Class II, division 1 malocclusion: a randomized clinical trial. Am J Orthod Dentofacial Orthop.Vol.114, N², pp:162-5.

Gianelly AA, Arena SA, Bernstein L. (1984): A comparison of Class II treatment changes noted with the light wire, edgewise, and Fränkel appliances. Am. J.Orthod.Vol.86, $\mathrm{N}^{\circ} 4$, pp:269-76.

Graber TM. (1971) : Serial Extraction. AmJ Orthod Vol.60, pp:541-575.

Graber TM., Profitt WR. (2007):Contemprary orthodontics. 4th St Louis,pp: 689- 707.

Guyer EC, Ellis EE 3rd, Mc Namara JA Jr (1986): Components of class III malocclusion in juveniles and adolescents. Angle orthod.Vol.56, Nº1, pp:7-30. 
Ingervall B, Thilander B. (1975) : Activity of temporal and masseter muscles in children with a lateral forced bite. Angle Orthod Vol.45, N4, pp:249-58.

Janson M, Hasund A (1981). : Functional problems in orthodontic patients out of retention. Eur J Orthod. Vol.3, N³, pp:173-9.

Kelly JE, Sanchez M, Van Kirk LE.(1973) : An assessment of the occlusion of teeth of children 6-11 Years. Washington, DC : National center for health Satatistics

Keski-Nisula K, and al. (2004):Occurrence of malocclusion and need of orthodontic treatment in early mixed dentition.Am J Orthod Dentofacial Orthop. Vol 125, N³, pp :20A

Hotz RP. (1947) : Active supervision of the eruption of the teeth by extraction. Trans Eur Orthod Soc, Vol.48, N³4,pp :47.

King EW. (1957) : Cervical anchorage in classe II, division 1 treatment: a cephalometric appraisal. Angle Orthod.,Vol.27, pp: 98-104

King EW. (1960) : Variation in profile change and their significance in timing treatment. Angle Orthod. Vol.30, pp :141-53

Kjellgren, Birger (1947): Serial extraction as a corrective procedure in dental orthopedic therapy,Trans. Eur. Orthod. Sot., pp. 134-160.

Kreit LH, Burstone C, Delman L. (1968) : Patient cooperation in orthodontic treatment. J Am Coll Dent. Vol.35, N4, pp:327-32.

Kurol J, Berglund L. (1992) Longitudinal study and cost-benefit analysis of the effect of early treatment of posterior cross-bites in the primary dentition. . Eur J OrthodVol.14, N³, pp:173-9.

Kutin G, Hawes RR.(1969) : Posterior cross-bites in the deciduous and mixed dentitions. Am J Ortthod. Vol.56, pp :491-504

Larsson E.(1986) : The effect of dummy-sucking on the occlusion: a review. Eur J orthodVol.8, $\mathrm{N}^{\circ} 2$, pp:127-30.

Linder-Aronson S. Adenoids. (1970) : Their effect on mode of breathing and nasal airflow and their relationship to characteristics of the facial skeleton and the dentition. A biometric, rhino-manometric and cephalometro-radiographic study on children with and without adenoids. Acta Otolaryngol SupplN²65, pp:1-132.

Little RM, Riedel RA, Engst ED.(1990):Serial extraction of first premolars-Postretention evaluation of stability and relapse. Angle Orthod ${ }^{\circ} 60$, pp:255-262.

McNamara JA.(1973): Neuromuscular and skeletal adaptations to altered function in the orofacial region. Am J Orthod.Vol.64, N6, pp:578-606

McNamara JA Jr, Bookstein FL, Shaughnessy T.(1985):Skeletal and dental changes following functional regulator therapy on class II patients. Am J Orthod.Vol.88, $\mathrm{N}^{\circ} 2$, pp:91-110.

McNamara JA Jr (1987) : An orthopedic approach to the treatment of Class III malocclusion in young patients. J Clin Orthod.Vol.21, N9, pp:598-608.

McNamara JA Jr, Brudow WL.(1993): Orthdodontic and orthodpedic treatment in the mixed dentition. Ann Arbor, Mich. : Needham Press.

McNamara JA Jr. (2002) :Early intervention in the transverse dimension: is it worth the effort? Am J Orthod Dentofacial OrthopVol.121, Nº, pp:572-4.

Nartallo-Turley PE, Turley PK.(1998): Cephalometric effects of combined palatal expansion and facemask therapy on Class III malocclusion. Am J Orthod. Vol.68, N³, pp:21724. 
Ngan P, Fields HW(1997): Open bite: a review of etiology and management. Pediatr Dent. Vol.19, N², pp:91-8.

O'Mullane DM. (1973) : Some factors predisposing to injuries of permanent incisors in school children. Br Dent J.Vol.17, N²8, pp:328-32.

Persson M, Persson E, Skagies S. (1989) : Long-term spontaneous changes following removal of all first premolars in Class I cases with crowding. EurJ Orthod Vol.11, pp:271-282.

Poulton DR. (1967): The influence of extraoral traction. Am J Orthod. Vol.53, N¹, pp:8-18.

Proffit WR, Fields HW, Moray LJ (1988) : Prevalence of malocclusion and orthodontic need in the United State estimate from the H-HANES III survey. Int J Adult Orthod Orthognath Surg. Vol.13, pp:97-106

Proffit WR, Tulloch JF. (2002) : Preadolescent Class II problems: treat now or wait? Am J Orthod Dentofacial OrthopVol.121, N6, pp:560-2.

Richardson A. (1981): A classification of open bite. Eur J Orthod. Vol.3, pp: 289-96

Righellis EG.(1983): Treatment effects of Fränkel, activator and extraoral traction appliances. Angle Orthod. Vol.53, N², pp:107-21.

Sakamoto T. (1981): Effective timing for the application of orthopedic force in the skeletal class III malocclusion. Am J Orthod. Vol.80, N4, pp:411-6.

Sassouni V. (1969) :A classification of skeletal facial types. Am J Orthod.Vol.55, N², pp:10923.

Stöckli PW, Willert HG.(1971): Tissue reactions in the temporomandibular joint resulting from anterior displacement of the mandible in the monkey. Am J Orthod.Vol.60, $\mathrm{N}^{\circ}$, pp:142-55

Sugawara J, Asano T, Endo N, Mitani H. (1990) : Long-term effects of chincap therapy on skeletal profile in mandibular prognathism.Am. J. Orthod.,Vol.98, N², pp:127-33.

Tollaro I, and al. (1983): Contiributo cefalometrico alla di daignosi del morso aperto. Nota 1: morso aperto scheletrico. Mondo Orthod. 1983; Vol.8, N³, pp: 47-59

Troelstrup B, Moller E. (1970) : Electromyography of the temporalis and masseter muscles in children with unilateral cross-bite. Scand J Dent Res.Vol.8, pp :425-30

Tulley WJ. (1969) : A critical appraisal of tongue-thrusting. Am J Orthod. Vol.55, N6, pp:64050.

Watson WG. (1972) : A computerized appraisal of the high-pull face-bow. Am J Orthod. Vol.62, N6, pp:561-79

Wieslander L ., Tandlakare L. (1963) : The effect of treatment on the concurrent development of the craniofacial complex. Am J Orthod.,Vol.49, pp : 15-27

Wigdorowicz-Makowerowa N, and al.(1979): Epidemiologic studies on prevalence and etiology of functional disturbances of the masticatory system. J.prosthet.Dent.Vol.41, $\mathrm{N}^{\circ} 1$, pp:76-82. 


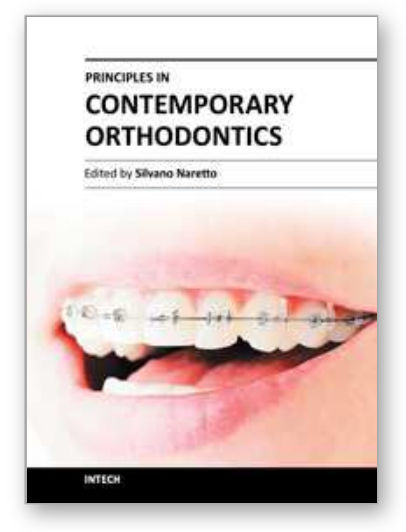

\author{
Principles in Contemporary Orthodontics \\ Edited by Dr. Silvano Naretto
}

ISBN 978-953-307-687-4

Hard cover, 584 pages

Publisher InTech

Published online 25, November, 2011

Published in print edition November, 2011

Orthodontics is a fast developing science as well as the field of medicine in general. The attempt of this book is to propose new possibilities and new ways of thinking about Orthodontics beside the ones presented in established and outstanding publications available elsewhere. Some of the presented chapters transmit basic information, other clinical experiences and further offer even a window to the future. In the hands of the reader this book could provide an useful tool for the exploration of the application of information, knowledge and belief to some orthodontic topics and questions.

\title{
How to reference
}

In order to correctly reference this scholarly work, feel free to copy and paste the following:

Ousehal Lahcen and Lazrak Laila (2011). Early Treatments in Orthodontics, Principles in Contemporary Orthodontics, Dr. Silvano Naretto (Ed.), ISBN: 978-953-307-687-4, InTech, Available from: http://www.intechopen.com/books/principles-in-contemporary-orthodontics/early-treatments-in-orthodontics

\section{INTECH}

open science | open minds

\author{
InTech Europe \\ University Campus STeP Ri \\ Slavka Krautzeka 83/A \\ 51000 Rijeka, Croatia \\ Phone: +385 (51) 770447 \\ Fax: +385 (51) 686166 \\ www.intechopen.com
}

\author{
InTech China \\ Unit 405, Office Block, Hotel Equatorial Shanghai \\ No.65, Yan An Road (West), Shanghai, 200040, China \\ 中国上海市延安西路65号上海国际贵都大饭店办公楼405单元 \\ Phone: +86-21-62489820 \\ Fax: +86-21-62489821
}


(C) 2011 The Author(s). Licensee IntechOpen. This is an open access article distributed under the terms of the Creative Commons Attribution 3.0 License, which permits unrestricted use, distribution, and reproduction in any medium, provided the original work is properly cited. 